\title{
Design, synthesis and structure-activity relationship studies of meridianin derivatives as novel JAK/STAT3 signaling inhibitors
}

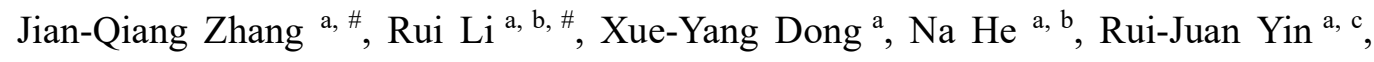

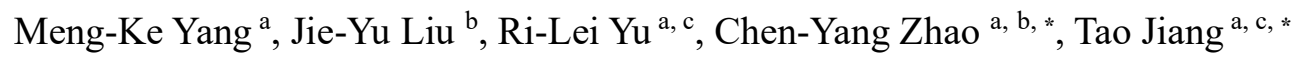 \\ ${ }^{a}$ Key Laboratory of Marine Drugs, Ministry of Education, School of medicine and Pharmacy, \\ Ocean University of China, Qingdao 266003, P.R. China \\ ${ }^{b}$ Innovation Platform of Marine Drug Screening \& Evaluation, Qingdao National Laboratory for \\ Marine Science and Technology, Qingdao 266100, Shandong, China \\ ${ }^{c}$ Laboratory for Marine Drugs and Bioproducts of Qingdao National Laboratory for Marine \\ Science and Technology, Qingdao 266237, China \\ ${ }^{*}$ Corresponding author. \\ E-mail addresses: jiangtao@ouc.edu.cn (T. Jiang); zhaocy@ouc.edu.cn (C. Zhao). \\ \# These authors contributed equally.
}

\begin{abstract}
Hyperactivation of Janus kinase (JAK)/signal transducer and activator of transcription 3 (STAT3) signaling is an attractive therapeutic target for tumor therapy. Herein, forty-eight novel meridianin derivatives were designed and synthesized, and their anti-tumor activity were evaluated in vitro both for activity optimization and structure-activity relationship (SAR) study. The results indicated that most derivatives exhibited significantly improved anti-tumor activity, especially for compound $\mathbf{6 e}$. The compound 6e contains an isothiouronium linked by an alkyl chain consisting of 6 carbon atoms with $\mathrm{IC}_{50}$ ranging from 1.11 to $2.80 \mu \mathrm{M}$ on various cancer cell lines. Consistently, 6e dose dependently induced the apoptosis of A549 and DU145 cells, in which STAT3 are constitutively active. Western blotting assays indicated that the phosphorylation levels of JAK1, JAK2 and STAT3 were inhibited by 6e at $5 \mu \mathrm{M}$ without significant change in total STAT3 level. Moreover, 6e also suppressed the
\end{abstract}


expressions of STAT3 downstream genes, including c-Myc, Cyclin D1 and Bcl-XL at $10 \mu \mathrm{M}$. An additional in vivo study revealed that $6 \mathrm{e}$ at the dose of $10 \mathrm{mg} / \mathrm{kg}$ could potently inhibit the DU145 xenograft tumor without obvious body-weight loss. These results clearly indicate that $\mathbf{6 e}$ could be a potential anti-tumor agent by targeting JAK/STAT3 signaling pathway.

Key words: JAK/STAT3 signaling pathway; Meridianin derivatives; Isothiouronium; Anti-tumor activity

\section{Introduction}

The Janus kinase (JAK) and Signal transducer and activator of transcription (STAT) signaling pathway is essential in the regulation of various biological processes, including immune responses, cell division, hematopoiesis and tumor formation [1-4]. Various cytokines and growth factors transmit signals through the JAK/STAT signaling pathway, which consists of tyrosine kinase-associated receptors, JAKs and downstream transcription factor STATs $[5,6]$. After stimulated by cytokines, such as type I and type II interferons or IL-6, the JAKs phosphorylate each other at tyrosine residues and then phosphorylate and activate STAT proteins, which themselves dimerize and translocate to the nucleus where they regulate gene transcription. Aberrant activation of the JAK/STAT signaling pathway has been closely associated with many diseases. Four members of the JAK family have been identified in mammals, including JAK1, JAK2, JAK3, and TYK2. The mammalian STAT family has 7 members comprising of STAT1-4, STAT5(a/b) and STAT6. Among them, STAT3 is the most well studied, who is broadly hyperactivated in variety of cancers, and closely associated with tumor cell proliferation and metastasis. Therefore, the JAK/STAT signaling pathway, especially STAT3 signaling, has emerged as a promising drug target for cancer treatment strategy.

Meridianins A-G (Figureure. S1) are marine-derived indole alkaloids isolated from the South Atlantic tunicate Aplidium meridianum, which have demonstrated to exhibit a number of biological activities, such as antitumor activity, protein kinase 
inhibitory activity in a low micromolar range, antimalarial activity, antituberculosis activity and anti-Alzheimer's disease activity [10-15]. In particular, they exhibit potent activity against the Clks and Dyrk kinase families, which are emerging as medicinally relevant targets involvement in cancer and Alzheimer's disease respectively [16]. Furthermore, Meijer and co-workers have found that the azaindole analogs of the meridianins, referred to as meriolins, are potent CDK9 inhibitors $[17,18]$. This potent activity, coupled with their antiproliferative properties, has established the meriolins as significant new leads for cancer therapeutics. Due to the promising biological activities and unique chemical structures, meridianins as lead compounds have attracted a great deal of interest in medicinal chemistry $[11,16,19]$.

These promising results led us to expand our effort in the synthesis of new diversely substituted meridianin derivatives. Herein, forty-eight novel meridianin derivatives were obtained in this study, and JAK/STAT3 hyperactivated human cancer cell lines were evaluated. The results indicated that meridianins (A, C, D and G) displayed weak cancer cell growth inhibition in four tested cell lines. By comparison, 1a $\mathbf{g}, 2 \mathbf{a} \sim \mathbf{g}, 3 \mathbf{3} \sim \mathbf{g}$ and $4 \mathbf{a} \sim \mathbf{g}$ showed significantly increased inhibitory activities, but remained to be improved.

Isothiourea is a positively charged group with significant pharmacological activities, such as anesthesia, anti-bacterial and an-titumor [19-25]. Our previous work showed that the isothiouronium-modified analogs had greatly enhanced anticancer activities in addition to their unique Golgi localization compared to the unmodified compounds [26].

With the aim of improving the anti-tumor activity, meridianins derivatives $\mathbf{5 a} \sim \mathbf{g}$ and $\mathbf{6 a} \sim \mathbf{g}$ were obtained by incorporating isothiourea groups at the N1-position with different length of carbon alkyl chains. The compound $\mathbf{6 e}$ exhibited better anti-tumor activity than positive control Gefitinib. To further investigate the structure-activity relationship, the analogues of compound 6e with different length of carbon alkyl chains or without isothiourea were obtained, and their anti-tumor activities were evaluated in the same cell lines. An additional in vivo study revealed that $\mathbf{6 e}$ exhibited significant anti-tumor activity. Finally, the possible mechanism of $\mathbf{6 e}$ was investigated 
preliminarily by molecular docking, western blot, flow cytometry analysis assay and immunohistochemistry (IHC) analyses.

\section{Results and Discussion}

\subsection{Chemistry}

The reaction sequence employed to synthesize the target compounds is outlined in Scheme 1 4.

The marine natural products indole alkaloids (meridianin A, C, D and G) were synthesized in four steps starting from commercially available indoles [27]. Firstly, the indolic nitrogen was protected by reaction with tosyl chloride in the presence of $\mathrm{NaOH}$ and in Acetonitrile, leading to the formation of compounds 2, 17 and 21 in $53 \%$ to $94 \%$ yields. Then, the $\mathrm{C}-3$ position of indoles was acetylated using acetic anhydride and aluminum chloride inmethylene chloride to give derivatives $\mathbf{3 , 1 8}$ and 22 in $73 \%$ to $79 \%$ yields. The enaminone intermediates proceeded with DMF/dimethylformamide-dimethylacetal (DMF-DMA) in 69\% to 79\% yield. Finally, compounds 1a $\mathbf{g}$, 3a $\mathbf{a}$ and $\mathbf{4 a} \sim \mathbf{g}$ were obtained from enaminone intermediates using 5 11 in 2-methoxyethanol in the presence of potassium carbonate in considerable yield (Scheme 1). As depicted in Scheme 2, the indolic nitrogen and 4-hydroxyl of compound 12 were tosyl chloride protected to get compounds $\mathbf{1 3}$ in $85 \%$ yield. Then the preparation of the corresponding $\mathbf{2} \mathbf{a} \sim \mathbf{g}$ derivatives was undertaken using a similar synthetic pathway in $38 \%$ to $66 \%$ yields. As shown in Scheme 3 and Scheme 4, isothiouronium derivatives $5 \mathbf{a} \sim \mathbf{g}, \mathbf{6 a} \sim \mathbf{g}$ and $\mathbf{6 e - 2} \sim \mathbf{6}$ were synthesized in medium yield by using introducing 1,6-dibromohexane or dibromoalkyl chain with different carbon chains without any purification and then boiling isopropanol in the presence of thiourea. In addition, the compounds 6e-1 was prepared by using introducing 1-bromohexane in $63 \%$ yield. 


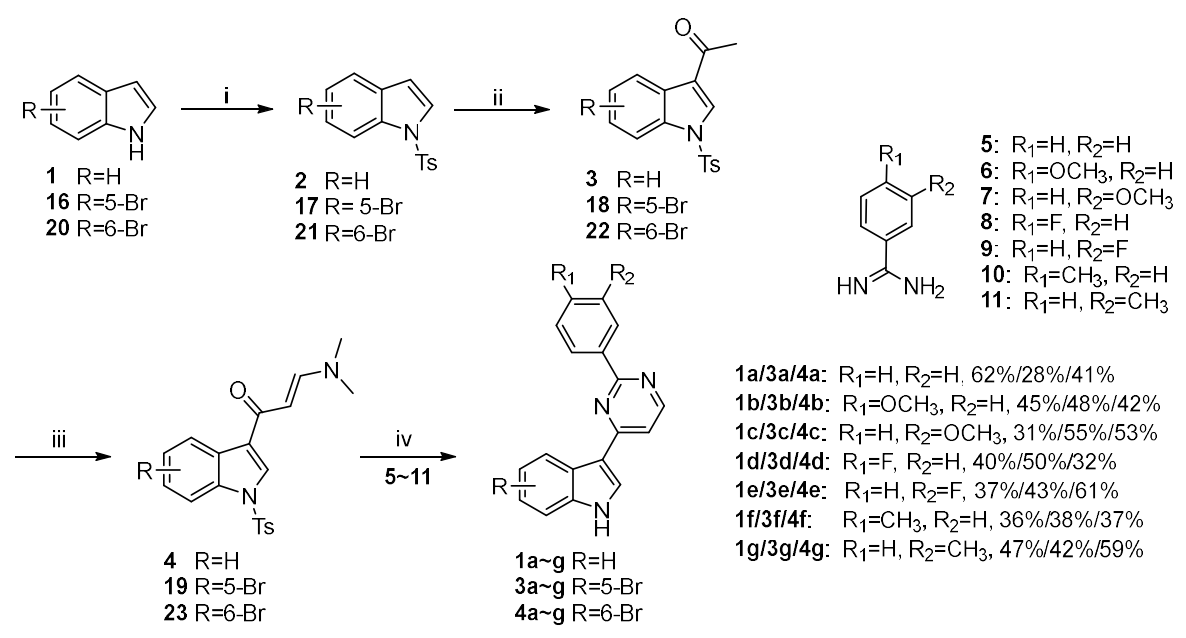

Scheme 1. Synthesis of Final Target Compounds 1a $\sim \mathbf{g}, \mathbf{3 a - g}$ and $\mathbf{4 a} \sim \mathbf{g}$. Reagents and conditions:

(i) $\mathrm{TsCl}, \mathrm{NaOH}, \mathrm{CH}_{3} \mathrm{CN}$, rt, 4 h; (ii) $\mathrm{Ac}_{2} \mathrm{O}, \mathrm{AlCl}_{3}, \mathrm{DCM}$, rt, 3 h; (iii) DMF-DMA, DMF, $110^{\circ} \mathrm{C}, 3$ h; (iv) $\mathrm{K}_{2} \mathrm{CO}_{3}, 2$-methoxyethanol, $120^{\circ} \mathrm{C}, 12 \mathrm{~h}$.

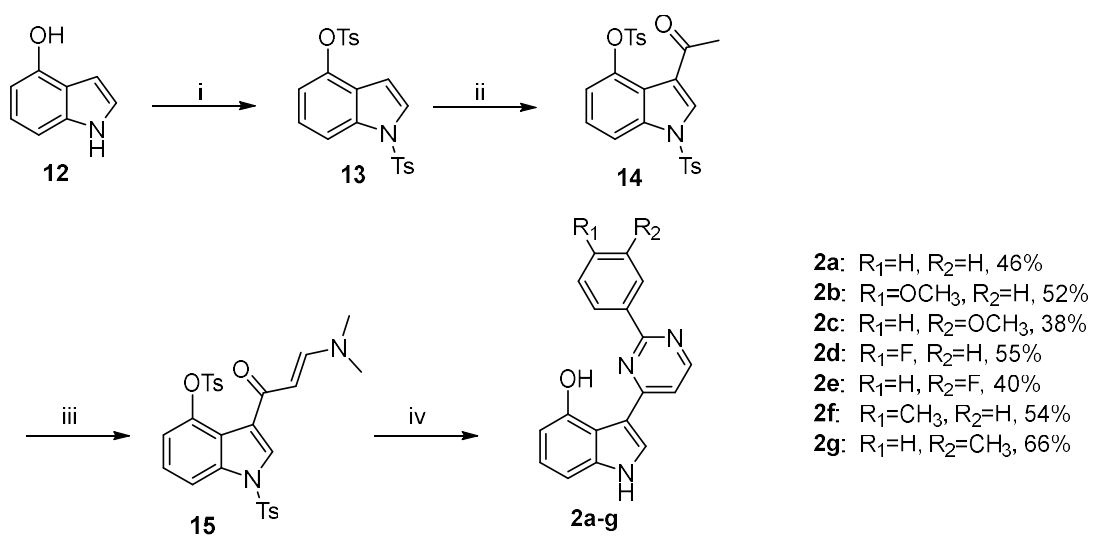

Scheme 2. Synthesis of Final Target Compounds 2a $\sim$ g. Reagents and conditions: (i) TsCl, $\mathrm{NaH}$, DMF, $0^{\circ} \mathrm{C}, 2$ h; (ii) $\mathrm{Ac}_{2} \mathrm{O}, \mathrm{AlCl}_{3}, \mathrm{DCM}$, rt, 3 h; (iii) DMF-DMA, DMF, $110^{\circ} \mathrm{C}, 3 \mathrm{~h}$; (iv) 5-11, $\mathrm{K}_{2} \mathrm{CO}_{3}$, 2-methoxyethanol, $120^{\circ} \mathrm{C}, 12 \mathrm{~h}$.

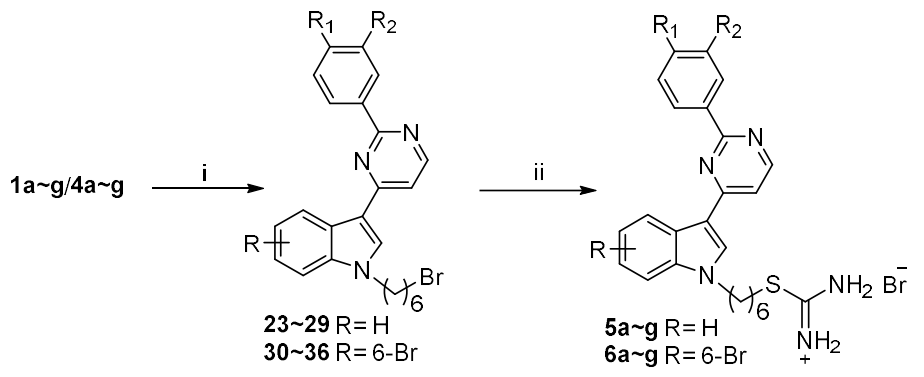

5a/6a: $\mathrm{R}_{1}=\mathrm{H}, \mathrm{R}_{2}=\mathrm{H}, 70 \% / 84 \%$, (2 steps) 5b/6b: $\mathrm{R}_{1}=\mathrm{OCH}_{3}, \mathrm{R}_{2}=\mathrm{H}, 78 \% / 68 \%$, (2 steps) 5c/6c: $\mathrm{R}_{1}=\mathrm{H}, \mathrm{R}_{2}=\mathrm{OCH}_{3}, 82 \% / 65 \%$, (2 steps) 5d6d: $R_{1}=F, R_{2}=H, 58 \% / 68 \%$, (2 steps) 5e/6e: $\mathrm{R}_{1}=\mathrm{H}, \mathrm{R}_{2}=\mathrm{F}, 77 \% / 75 \%$, (2 steps) 5f/6f: $\quad \mathrm{R}_{1}=\mathrm{CH}_{3}, \mathrm{R}_{2}=\mathrm{H}, 60 \% / 69 \%$. (2 steps) 5g/6g: $\mathrm{R}_{1}=\mathrm{H}, \mathrm{R}_{2}=\mathrm{CH}_{3}, 74 \% / 80 \%$, (2 steps)

Scheme 3. Synthesis of Final Target Compounds 5a $\sim \mathbf{g}$ and $\mathbf{6 a} \sim \mathbf{g}$. Reagents and conditions: (i) 


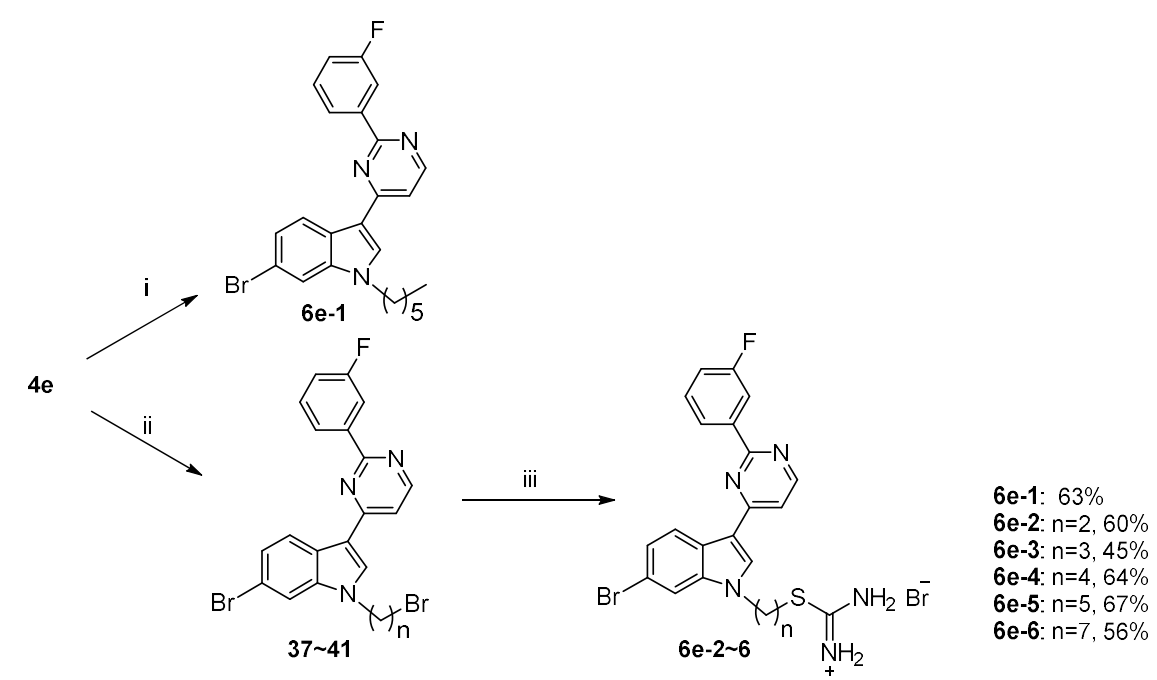

Scheme 4. Synthesis of Final Target Compounds 6e-1 6. Reagents and conditions: (i) 1-bromohexane, $\mathrm{K}_{2} \mathrm{CO}_{3}$, DMF, 50ㄷ 12 h; (ii) Dibromoalkyl chain, $\mathrm{K}_{2} \mathrm{CO}_{3}$, DMF, $50^{\circ} \mathrm{C} 12$ h; (iii) Thiourea, isopropanol, $80^{\circ} \mathrm{C}, 14 \mathrm{~h}$.

\subsection{Biological activity assessments}

\subsubsection{Cell viability assay and SAR analysis}

To evaluate the anti-tumor activities of meridianin A, C, D, G and their derivatives, four JAK/STAT3 over-activated human cancer cell lines HeLa, MDA-MB-231, A549 and DU145 were examined. Initially, meridianins (A, C, D and G) and their derivatives $\mathbf{1 a} \sim \mathbf{g}, \mathbf{2} \mathbf{a} \sim \mathbf{g}, \mathbf{3 a} \mathbf{\mathbf { g }}$ and $\mathbf{4 a} \sim \mathbf{g}$ were prepared and evaluated for cell growth inhibitory activities against cancer cell lines (Table 1). The results indicated that meridianin A, C, D and G displayed weak cancer cell growth inhibition in four tested cell lines. By comparison, meridianin derivatives 1a $\mathbf{g}, \mathbf{2 a} \sim \mathbf{g}, \mathbf{3 a} \sim \mathbf{g}$ and 4a $\mathbf{g}$ showed significantly increased inhibitory activities. With the aim of improving the antitumor activity, compounds $5 \mathbf{a} \sim \mathbf{g}$ and $\mathbf{6 a} \sim \mathbf{g}$ were obtained by incorporating isothiourea groups at the C1-position of meridianins $\mathrm{D}$ and $\mathrm{G}$ with different length of carbon alkyl chains. Notably, the anti-tumor effects of the compounds were significantly enhanced, almost all compounds with $\mathrm{IC}_{50}$ less than $10 \mu \mathrm{M}$ (Table 2). 
Among them, the most potent compound 6e inhibited the growth of HeLa, MDA-MB-231, A549 and DU145 cells with $\mathrm{IC}_{50}$ values of 1.11, 1.22, 2.80 and 1.13 $\mu \mathrm{M}$, which exhibited better activity than positive control (Gefitinib), respectively. Based on the above results, the analogues of compound $\mathbf{6 e}$ with different carbon chain lengths or without isothiourea were obtained, and the anti-tumor activity results in Table 3. The structure-activity relationship suggesting that reducing or increasing the number of carbon atoms will lead to the decrease of antiproliferative activity. On the other hand, compound 6e-1 was found to be completely inactive with $\mathrm{IC}_{50}$ values greater than $100 \mu \mathrm{M}$, indicating that the substitution of isothiourea group significantly contributed to the antitumor activity.

Table 1. Antiproliferative activity of meridianin A, C, D, G and their derivatives against human cancer cell lines.

\begin{tabular}{ccccc}
\hline \multirow{2}{*}{ Cpd. } & \multicolumn{4}{c}{$\mathrm{IC}_{50} \pm \mathrm{SD}(\mu \mathrm{M})^{\mathrm{a}}$} \\
\cline { 2 - 5 } 1a & $4.50 \pm 0.41$ & $4.39 \pm 0.23$ & $10.86 \pm 0.52$ & $39.16 \pm 2.21$ \\
1b & $11.72 \pm 2.14$ & $4.75 \pm 0.28$ & $>100$ & $46.92 \pm 1.31$ \\
$\mathbf{1 c}$ & $2.33 \pm 0.03$ & $4.23 \pm 0.68$ & $7.46 \pm 0.54$ & $12.61 \pm 2.07$ \\
$\mathbf{1 d}$ & $4.35 \pm 0.20$ & $5.25 \pm 0.27$ & $11.45 \pm 0.95$ & $16.71 \pm 2.28$ \\
$\mathbf{1 e}$ & $6.18 \pm 0.16$ & $>100$ & $7.10 \pm 0.01$ & $>100$ \\
$\mathbf{1 f}$ & $>100$ & $14.48 \pm 0.59$ & $8.84 \pm 0.45$ & $23.88 \pm 2.82$ \\
$\mathbf{1 g}$ & $1.56 \pm 0.09$ & $8.57 \pm 0.65$ & $7.11 \pm 0.31$ & $11.23 \pm 0.65$ \\
$\mathbf{2 a}$ & $3.76 \pm 0.28$ & $8.46 \pm 1.24$ & $7.63 \pm 0.73$ & $34.17 \pm 3.72$ \\
$\mathbf{2 b}$ & $4.16 \pm 0.11$ & $8.59 \pm 0.64$ & $9.40 \pm 0.64$ & $29.15 \pm 3.45$ \\
$\mathbf{2 c}$ & $2.15 \pm 0.11$ & $3.03 \pm 0.50$ & $4.25 \pm 0.23$ & $17.79 \pm 0.83$ \\
$\mathbf{2 d}$ & $9.05 \pm 0.61$ & $13.11 \pm 1.51$ & $28.74 \pm 8.43$ & $>100$ \\
$\mathbf{2 e}$ & $2.86 \pm 0.27$ & $5.21 \pm 0.24$ & $5.12 \pm 0.23$ & $13.70 \pm 4.37$ \\
$\mathbf{2 f}$ & $1.81 \pm 0.04$ & $8.13 \pm 0.15$ & $3.50 \pm 0.08$ & $8.86 \pm 0.68$ \\
$\mathbf{2 g}$ & $2.70 \pm 0.18$ & $35.22 \pm 2.40$ & $17.15 \pm 1.41$ & $22.61 \pm 2.47$ \\
& & & &
\end{tabular}




\begin{tabular}{ccccc} 
3a & $2.99 \pm 0.44$ & $11.30 \pm 1.38$ & $8.95 \pm 0.68$ & $19.08 \pm 1.19$ \\
$\mathbf{3 b}$ & $4.86 \pm 0.16$ & $6.25 \pm 0.34$ & $7.73 \pm 0.38$ & $10.46 \pm 0.45$ \\
$\mathbf{3 c}$ & $4.95 \pm 0.04$ & $7.46 \pm 1.76$ & $15.78 \pm 1.11$ & $27.57 \pm 3.75$ \\
$\mathbf{3 d}$ & $26.63 \pm 1.05$ & $25.48 \pm 1.70$ & $>100$ & $>100$ \\
$\mathbf{3 e}$ & $6.58 \pm 0.16$ & $9.69 \pm 0.72$ & $9.75 \pm 0.87$ & $12.85 \pm 0.56$ \\
$\mathbf{3 f}$ & $7.37 \pm 1.22$ & $>100$ & $10.02 \pm 2.05$ & $45.16 \pm 2.44$ \\
$\mathbf{3 g}$ & $25.04 \pm 0.82$ & $>100$ & $>100$ & $>100$ \\
$\mathbf{4 a}$ & $25.07 \pm 3.57$ & $20.23 \pm 2.09$ & $25.07 \pm 3.57$ & $>100$ \\
$\mathbf{4 b}$ & $8.05 \pm 0.85$ & $8.60 \pm 0.64$ & $21.68 \pm 1.70$ & $>100$ \\
$\mathbf{4 c}$ & $2.55 \pm 0.33$ & $4.76 \pm 0.37$ & $9.49 \pm 0.10$ & $24.65 \pm 0.50$ \\
$\mathbf{4 d}$ & $10.56 \pm 0.42$ & $9.06 \pm 0.32$ & $22.50 \pm 2.78$ & $18.08 \pm 2.44$ \\
$\mathbf{4 e}$ & $17.53 \pm 1.05$ & $27.46 \pm 1.26$ & $>100$ & $32.60 \pm 1.42$ \\
$\mathbf{4 f}$ & $5.03 \pm 0.70$ & $8.56 \pm 0.87$ & $11.84 \pm 1.29$ & $26.01 \pm 2.83$ \\
$\mathbf{4 g}$ & $1.67 \pm 0.11$ & $4.23 \pm 0.06$ & $10.04 \pm 0.44$ & $19.81 \pm 0.28$ \\
Meridianin A & $25.39 \pm 0.35$ & $>100$ & $>100$ & $>100$ \\
Meridianin C & $24.07 \pm 0.16$ & $14.03 \pm 2.63$ & $23.54 \pm 3.20$ & $>100$ \\
Meridianin D & $13.17 \pm 2.71$ & $>100$ & $26.68 \pm 0.63$ & $>100$ \\
\hline Meridianin G & $22.52 \pm 3.55$ & $>100$ & $>100$ & $>100$ \\
\hline & & & & \\
\hline
\end{tabular}

${ }^{a}$ The inhibitory effects of the compounds on the proliferation of the four cell lines were determined by the MTT assay. Results are expressed as means \pm SD. All experiments were independently performed at least three times.

Table 2. Antiproliferative activity of meridianin (D and G) derivatives against human cancer cell lines.

\begin{tabular}{ccccc}
\hline \multirow{2}{*}{ Cpd. } & \multicolumn{4}{c}{$\mathrm{IC}_{50} \pm \mathrm{SD}(\mu \mathrm{M})^{\mathrm{a}}$} \\
\cline { 2 - 5 } & $\mathrm{HeLa}$ & $\mathrm{MDA}-\mathrm{MB}-231$ & $\mathrm{~A} 549$ & $\mathrm{DU} 145$ \\
\hline $\mathbf{5 a}$ & $14.56 \pm 2.05$ & $18.61 \pm 1.10$ & $8.68 \pm 0.27$ & $22.70 \pm 2.03$ \\
$\mathbf{5 b}$ & $4.21 \pm 0.15$ & $4.67 \pm 0.17$ & $2.68 \pm 0.30$ & $6.04 \pm 0.10$ \\
$\mathbf{5 c}$ & $7.53 \pm 0.41$ & $7.99 \pm 0.82$ & $8.85 \pm 0.06$ & $18.56 \pm 3.40$
\end{tabular}




\begin{tabular}{ccccc}
$\mathbf{5 d}$ & $6.92 \pm 0.23$ & $5.46 \pm 0.10$ & $5.76 \pm 0.12$ & $6.67 \pm 0.21$ \\
$\mathbf{5 e}$ & $8.31 \pm 1.00$ & $5.87 \pm 0.21$ & $8.23 \pm 0.64$ & $10.20 \pm 0.15$ \\
$\mathbf{5 f}$ & $4.70 \pm 0.08$ & $2.95 \pm 0.11$ & $5.84 \pm 0.25$ & $6.47 \pm 0.28$ \\
$\mathbf{5 g}$ & $2.19 \pm 0.09$ & $1.92 \pm 0.11$ & $3.65 \pm 0.07$ & $3.86 \pm 0.31$ \\
$\mathbf{6 a}$ & $3.28 \pm 0.08$ & $4.59 \pm 0.13$ & $4.81 \pm 0.21$ & $5.04 \pm 0.06$ \\
$\mathbf{6 b}$ & $9.23 \pm 0.99$ & $6.80 \pm 1.33$ & $6.94 \pm 0.07$ & $8.91 \pm 0.55$ \\
$\mathbf{6 c}$ & $3.49 \pm 0.13$ & $3.20 \pm 0.02$ & $5.00 \pm 0.31$ & $5.46 \pm 0.09$ \\
$\mathbf{6 d}$ & $7.73 \pm 0.26$ & $5.61 \pm 0.16$ & $9.86 \pm 0.46$ & $7.01 \pm 0.32$ \\
$\mathbf{6 e}$ & $1.11 \pm 0.04$ & $1.22 \pm 0.34$ & $2.80 \pm 0.18$ & $1.13 \pm 0.17$ \\
$\mathbf{6 f}$ & $9.34 \pm 0.72$ & $4.89 \pm 0.16$ & $7.32 \pm 0.35$ & $4.74 \pm 0.03$ \\
$\mathbf{6 g}$ & $2.42 \pm 0.15$ & $5.51 \pm 0.03$ & $8.93 \pm 1.07$ & $6.38 \pm 0.31$ \\
Gefitinib & $7.51 \pm 0.45$ & $32.65 \pm 0.31$ & $13.08 \pm 0.28$ & $9.18 \pm 0.06$ \\
\hline
\end{tabular}

${ }^{a}$ The inhibitory effects of the compounds on the proliferation of the four indicated cell lines were determined by the MTT assay. Results are expressed as means \pm SD. All experiments were independently performed at least three times.

Table 3. Antiproliferative activity of compound $\mathbf{6 e}$ analogs against human cancer cell lines.

\begin{tabular}{ccccc}
\hline \multirow{2}{*}{ Cpd. } & \multicolumn{4}{c}{$\mathrm{IC}_{50} \pm \mathrm{SD}(\mu \mathrm{M})^{\mathrm{a}}$} \\
\cline { 2 - 5 } & HeLa & MDA-MB-231 & A549 & DU145 \\
\hline $\mathbf{6 e}-1$ & $>100$ & $>100$ & $>100$ & $>100$ \\
$\mathbf{6 e - 2}$ & $>100$ & $24.31 \pm 0.77$ & $>100$ & $29.18 \pm 0.85$ \\
$\mathbf{6 e - 3}$ & $11.28 \pm 0.77$ & $9.65 \pm 0.30$ & $9.49 \pm 1.18$ & $15.30 \pm 3.10$ \\
$\mathbf{6 e - 4}$ & $8.19 \pm 0.08$ & $8.38 \pm 1.07$ & $8.85 \pm 0.30$ & $10.73 \pm 0.91$ \\
$\mathbf{6 e - 5}$ & $4.92 \pm 0.09$ & $7.88 \pm 0.11$ & $7.80 \pm 0.19$ & $7.55 \pm 0.73$ \\
$\mathbf{6 e - 6}$ & $12.08 \pm 1.26$ & $14.21 \pm 0.37$ & $10.42 \pm 0.27$ & $10.32 \pm 2.16$ \\
\hline
\end{tabular}

${ }^{a}$ The inhibitory effects of the compounds on the proliferation of the four cell lines were determined by the MTT assay. Results are expressed as means \pm SD. All experiments were independently performed at least three times. 


\subsubsection{Compound $6 \mathbf{e}$ induces cell apoptosis}

The effect of compound $\mathbf{6 e}$ on inducing tumor cell apoptosis was analyzed in Figureure. 1. A549 and DU145 cells were incubated with 6e at different concentrations for $24 \mathrm{~h}$. Annexin V-FITC/PI staining was carried out and the percentages of apoptotic cells were further determined using flow cytometry. The results showed that 6e dose dependently induced the apoptosis of A549 and DU145 cells. As shown in Figure. 1, in A549, the induced apoptosis rates at 0, 1, 5, and 10 $\mu \mathrm{M}$ were $2.59 \%, 4.30 \%, 14.78 \%$ and $45.40 \%$, respectively. In DU145, the induced apoptosis rates at $0,1,5$, and $10 \mu \mathrm{M}$ were $2.10 \%, 5.19 \%, 5.32 \%$ and $19.25 \%$, respectively.

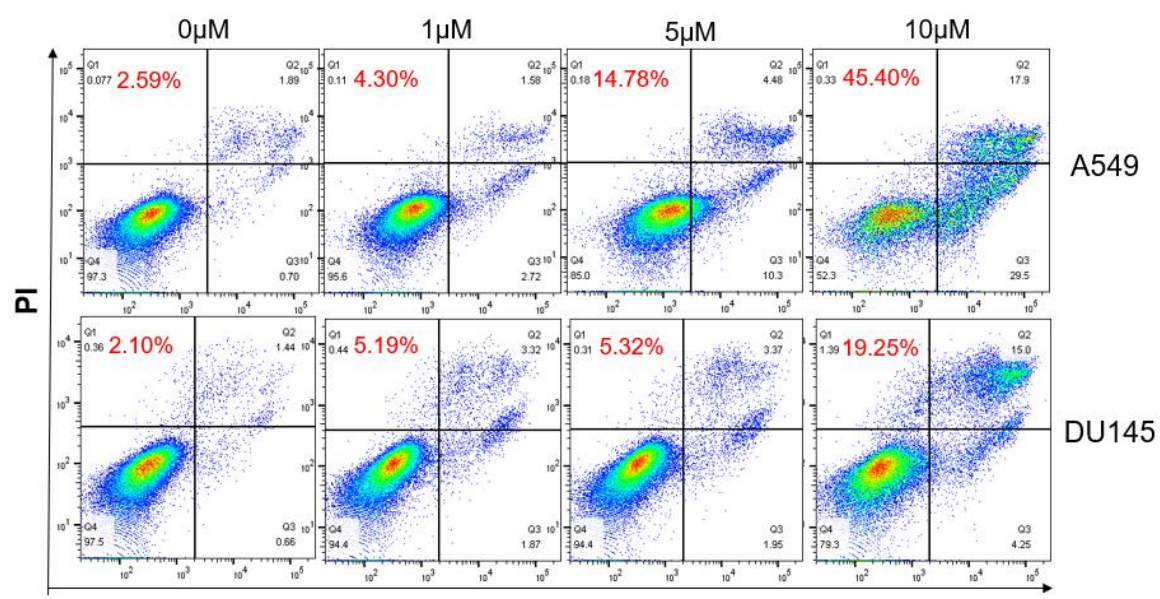

Annexin V-FITC

Figureure. 1. Compound 6e induced A549 and DU145 cancer cells apoptosis in Vitro. A549 and DU145 cells were incubated with 6e at different concentrations $(0-10 \mu \mathrm{M})$ for $24 \mathrm{~h}$. Annexin V/PI staining was carried out and the percentages of apoptotic cells were further determined using flow cytometry.

\subsubsection{Molecular docking}

Molecular docking was performed for understanding the interaction mechanisms between compound 6e with JAK1 (PDB ID:4I5C), JAK2 (PDB ID:5CF5) and STAT3 (PDB ID:1BG1) [28], respectively. The results showed that the hydrophobic fatty chain was accommodated at a hydrophobic pocket mainly defined by residues Leu881, Va1889, Ala906, Va1938, Phe958, Leu959 and Leu1010 (Figureure. 2 A). The 
hydrogen in the imine of 6e engages H-bonds formation with Glu957 and Gly1020. For JAK2, the docking poses suggested that the imine group of $6 \mathbf{e}$ interacts with a carboxyl group of Asp994 and carbonyl group of Gly861 by forming two hydrogen bonds (Figureure. 2 B). In addition, nitrogen of imine on 6e also forms salt bridge interaction with Asp994. The Phe710 forms $\pi-\pi$ interactions with the indole ring of $6 \mathbf{e}$, while the Glu652 forms a hydrogen bond and a salt-bridge with the $\mathrm{H}$ atom and the $\mathrm{N}$ atom on imine, respectively (Figureure. 2 C) [29].

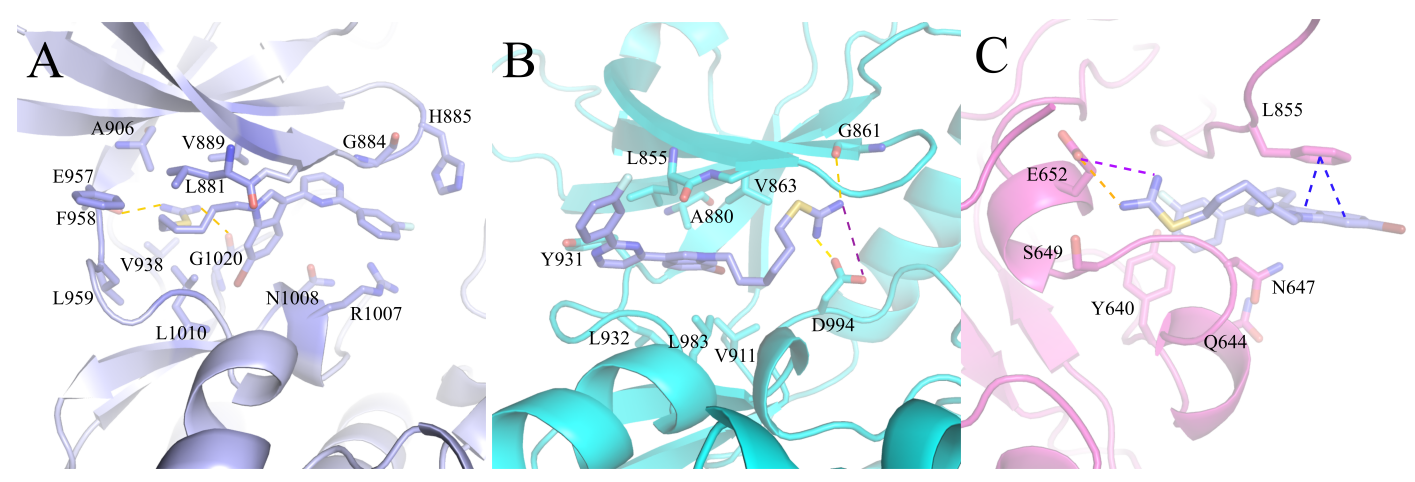

Figureure. 2. Binding modes of the compound 6 e with JAK1, JAK2 and STAT3. The compound 6e was shown in blue, while the JAK1 (A), JAK2 (B) and STAT3 (C) were shown in purple, blue and pink, respectively. The H-bonds, $\pi-\pi$ or salt-bridges were shown in dashed lines.

\subsubsection{Compound 6e inhibit expression of JAK/STAT3 target genes}

The ability of compound $\mathbf{6 e}$ to inhibit the phosphorylation of JAK/STAT3 was determined in A549 and DU145 cells. As shown in Figure. 3A and 3B, after $24 \mathrm{~h}$ treatment with $5 \mu \mathrm{M}$ 6e, the decreased levels of JAK1, JAK2 and STAT3 were observed at both in A549 and DU145 cells, but no significant change was with total STAT3 protein expression. Moreover, compound 6 e significantly inhibited the expression of JAK/STAT3 downstream genes c-Myc, Cyclin D1 and Bcl-XL at $10 \mu \mathrm{M}$ after $24 \mathrm{~h}$ treatment (Figureure. 3C). Therefore, pretreatment with compound 6e suppressed JAK/STAT3 signaling pathway and its downstream genes expression, which were consistent with the above results obtained in vitro. 


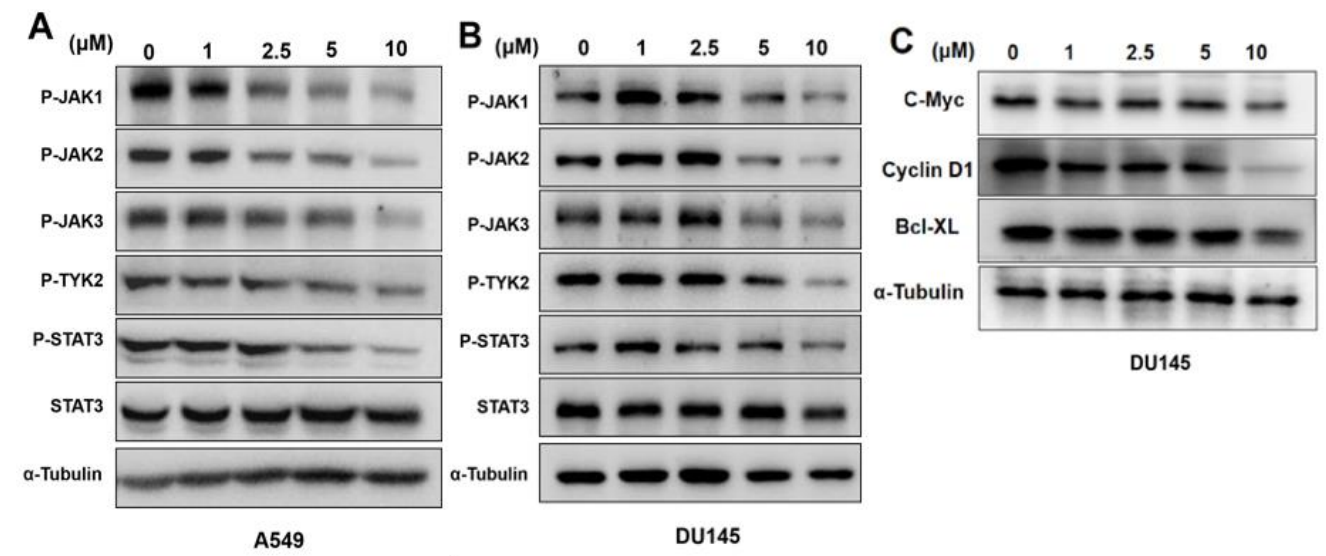

Figure. 3. The effect of $\mathbf{6 e}$ on overexpression protein in JAK/STAT3 signaling pathway by western blot analysis

\subsubsection{Compound 6e inhibited tumor growth in a mouse breast cancer model}

To further investigate the antitumor potential in vivo, we evaluated the effects of compound 6e in nude mice tumor model (Figure. 4). After the solid tumor was established, twenty-four nude mice were randomly divided into four groups, which were vehicle control group, 6e groups $(5 \mathrm{mg} / \mathrm{kg}$ and $10 \mathrm{mg} / \mathrm{kg})$ and Gefitinib positive control group. All the compound were taken by intragastric gavage. Compound $\mathbf{6 e}$ at the dose of $10 \mathrm{mg} / \mathrm{kg}$ could significantly inhibit tumor growth, and the tumor inhibition rate of $6 \mathbf{e}$ was over $40 \%$, which was comparable to that of the positive control (Figure. 4A, 4B and 4C). Subsequently, Ki67 and Tunel staining were performed on tumor sections, which showed that tumor proliferation marker Ki67 was significantly inhibited, and the proportion of apoptotic cells that were marked by Tunel positive staining also significantly increased with 6e treatment at a dose of 10 $\mathrm{mg} / \mathrm{kg}$ (Figure. 4D). Moreover, during the administration period, the weight of nude mice did not increase or decrease significantly (Figure. 4E), indicating that there is no obvious biological toxicity of $\mathbf{6 e}$. 
A

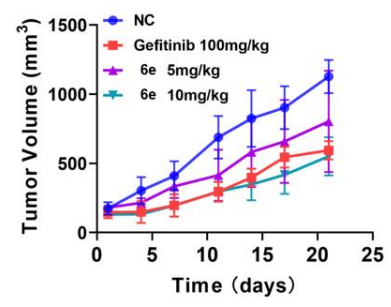

D

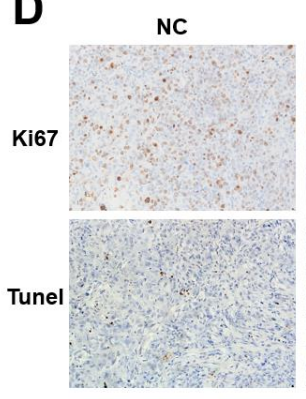

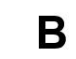

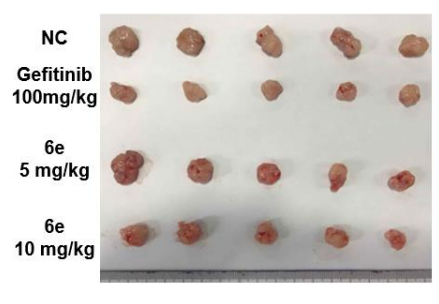

$6 \mathrm{e} 5 \mathrm{mg} / \mathrm{kg}$

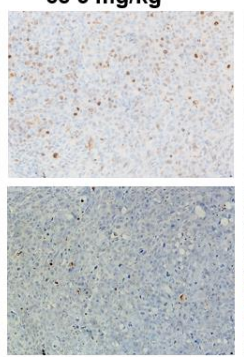

$6 \mathrm{e} 10 \mathrm{mg} / \mathrm{kg}$

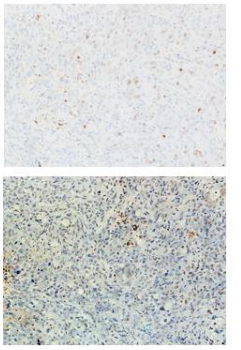

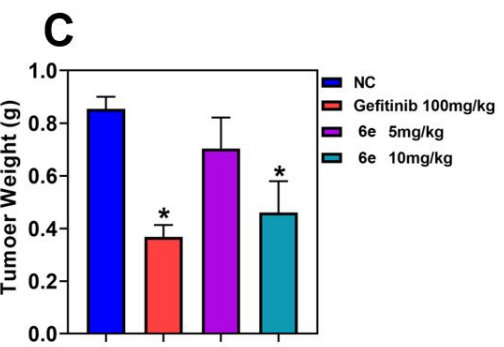

E

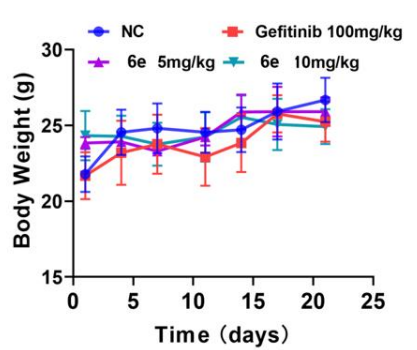

Figure. 4. The results of $6 \mathbf{e}$ on DU145 tumor bearing model in vivo therapeutic. (A) Growth curve of subcutaneous tumor bearing DU145 treated with 6e. (B) Anatomical mice's tumor tissues treated with 6e. (C) The weight of tumors in each group treated with 6e. (D) Ki67 and Tunel staining in DU145 tumors treated with different doses of 6e. (E) Changes in body weight of mice in each group during administration.

\subsubsection{Immunohistochemical (IHC) analysis}

To further test the inhibitory effects of $\mathbf{6 e}$ to JAK/STAT3 signaling, IHC analysis of nude mice inoculated with DU145 tumor cells were performed. As shown in Figure. 5, after 6e treatment, the intratumoral staining of p-STAT3, Cyclin D1 and c-Myc in DU145 inoculated mice were significantly lower than those in the NC group, and their staining levels decreased while the dose of $\mathbf{6 e}$ increasing. Therefore, compound $\mathbf{6 e}$ may exert antitumor effects by inhibiting the JAK/STAT3 signaling pathway both in vitro and in vivo. 


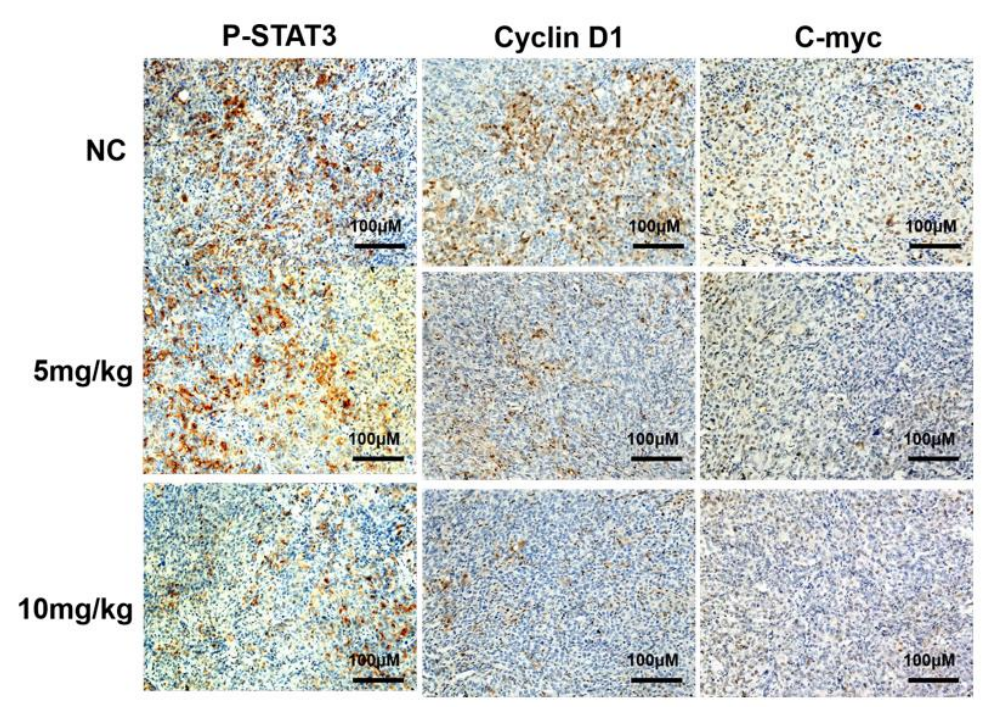

Figure. 5. Immunohistochemistry of protein expressions in DU145 xenograft model. Formalin-fixed paraffin-embedded sections from DU145 xenograft tumors were stained with H\&E stain, p-STAT3, Cyclin D1 and c-Myc antibodies.

\section{Conclusions}

In summary, a novel series of meridianin derivatives were obtained and biologically evaluated. Initially, meridianins (A, C, D and G) and their four series derivatives of compounds $1 \mathbf{a} \sim \mathbf{g}, \mathbf{2 a} \sim \mathbf{g}, \mathbf{3 a} \sim \mathbf{g}$ and $\mathbf{4 a} \sim \mathbf{g}$ were prepared, the results indicated that meridianins (A, C, D and G) displayed weak inhibitory activity on four JAK/STAT3 over-activated human cancer cell lines HeLa, MDA-MB-231, A549 and DU145, whereas most of the meridianin derivatives exerted promising inhibitory activity on tested cell lines. To improve the anti-tumor activity, meridianins derivatives $\mathbf{5 a} \sim \mathbf{g}$ and $\mathbf{6 a} \sim \mathbf{g}$ were designed and synthesized by incorporating isothiourea groups at the N1-position with different length of carbon alkyl chains. Surprisingly, the anti-tumor effects of the isothiouronium-modified compounds were significantly enhanced, with $\mathrm{IC}_{50}$ less than $10 \mu \mathrm{M}$. Among them, the most potent compound 6e with alkyl chain of six carbon atoms had an $\mathrm{IC}_{50}$ ranged in 1.11-2.80 $\mu \mathrm{M}$ in various cancer cell lines, which is superior to the positive control Gefitinib. Structure-activity relationship (SAR) study indicated that isothiouronium-modified by $\mathrm{N}$-alkylation with 6C alkyl chains may contribute most to anti-tumor activity. Western 
blotting assays suggested that treatment with compound 6e could decrease the phosphorylation level of JAK1, JAK2 and STAT3 at $5 \mu \mathrm{M}$, but did not affect the total STAT3 level. Moreover, 6e also suppressed the expressions of STAT3 downstream gene, including c-Myc, Cyclin D1 and Bcl-XL. Consistently, 6e dose dependently induced the apoptosis of A549 and DU145 cells. Molecular docking studies demonstrated that $\mathrm{H}$-bond is the main type of interaction between compound $\mathbf{6 e}$ and JAK1/JAK2 kinases, and 6e could also tightly bind to STAT3 SH2 domain. An additional in vivo study revealed that application of $6 \mathbf{e}$ at the dose of $10 \mathrm{mg} / \mathrm{kg}$ could significantly inhibit the DU145 xenograft tumor growth without obvious body-weight loss, which was comparable to that of the positive control. Taken together, these results clearly indicated that 6 e could be a highly potent anti-tumor agent by targeting JAK/STAT3 signaling pathway.

\section{Materials and Methods}

\subsection{Chemistry}

All commercially available starting materials and solvents were purchased from commercial vendors and used without further purification. Reactions were monitored using analytical thin layer chromatography (TLC) on precoated silica gel GF254 plates (Qingdao Haiyang Chemical Plant, Qingdao, China) plates and visualized under ultraviolet light (254 $\mathrm{nm}$ and $365 \mathrm{~nm}$ ). Column chromatography was performed on silica gel (200-300 mesh). Melting points were determined on a Mitamura-Riken micro-hot stage and uncorrected. ${ }^{1} \mathrm{H}$ and ${ }^{13} \mathrm{C}$ NMR spectra were recorded on the Broker AVANCE NEO and Agilent DD2 500 with 400 or $500 \mathrm{MHz}$ for proton $\left({ }^{1} \mathrm{H}\right.$ NMR), and 100 or $125 \mathrm{MHz}$ for carbon $\left({ }^{13} \mathrm{C} \mathrm{NMR}\right)$, respectively. The chemical shifts $(\delta)$ were expressed in parts per million (ppm) downfield and coupling constants $(J)$ values were described as hertz. High resolution (ESI) MS spectra were recorded using a QTOF-2 Micromass spectrometer. The purity of final compounds for biological evaluation was higher than $95 \%$ by analytical HPLC analysis with Primaide 1210 system.

Compounds 1-4, 16-19 and 20-23 were prepared according to the procedure 
published by Dong et al. and the spectroscopic data for intermediates were identical to those described in literature [30].

\subsubsection{General procedure for synthesis of $\mathbf{1} \mathbf{a} \sim \mathbf{g}, \mathbf{3} \mathbf{a} \sim \mathbf{g}$ and $\mathbf{4 a} \sim \mathbf{g}$ meridianin analogs.}

To the solution of intermediates 4, 19 or 23 (1.0 equiv.) in 2-methoxyethanol (5 $\mathrm{mL}$ ) were added 5 11 (2.5 equiv.) and potassium carbonate (2.0 equiv.) respectively. The reaction mixture was stirred at $120^{\circ} \mathrm{C}$ for $20 \mathrm{~h}$ under a nitrogen atmosphere. Then, the mixture was poured into ice water and extracted with ethyl acetate $(3 \times 50 \mathrm{~mL})$. The combined organic layers were washed with brine and dried over magnesium sulfate anhydrous. After filtration, the solvent was removed under vacuum and the residue was purified by silica gel column chromatography (petroleum ether/ethyl acetate 10:1) to give get the final target compounds $\mathbf{1 a} \sim \mathbf{g}, \mathbf{3} \mathbf{a} \sim \mathbf{g}$ and $\mathbf{4 a} \sim \mathbf{g}$.

3-(2-phenylpyrimidin-4-yl)-1H-indole (1a). Yield: 62\%; pale yellow solid; m.p. 137-139 ${ }^{\circ} \mathrm{C}$; ${ }^{1} \mathrm{H}$ NMR (500 MHz, DMSO-d $): \delta 11.94(\mathrm{~s}, 1 \mathrm{H}), 8.75-8.71(\mathrm{~m}, 1 \mathrm{H})$, $8.68(\mathrm{~d}, J=7.6 \mathrm{~Hz}, 1 \mathrm{H}), 8.54$ (d, $J=7.0 \mathrm{~Hz}, 2 \mathrm{H}), 8.50$ (d, $J=2.5 \mathrm{~Hz}, 1 \mathrm{H}), 7.83$ (d, $J$ $=5.3 \mathrm{~Hz}, 1 \mathrm{H}), 7.60(\mathrm{t}, J=7.2 \mathrm{~Hz}, 2 \mathrm{H}), 7.57-7.55(\mathrm{~m}, 1 \mathrm{H}), 7.53(\mathrm{~d}, J=7.8 \mathrm{~Hz}, 1 \mathrm{H})$, 7.31-7.22 (m, 2H); ${ }^{13} \mathrm{C}$ NMR (125 MHz, DMSO-d $): \delta 163.78,162.85,157.10$, $138.72,137.86,131.09,130.25,129.25,128.23,125.80,122.92,122.25,121.60$, 114.68, 113.87, 112.81; HRMS: $m / z[\mathrm{M}+\mathrm{H}]^{+}$calcd for $\mathrm{C}_{18} \mathrm{H}_{13} \mathrm{~N}_{3}, 272.1182$; found, 272.1189 .

3-(2-(4-methoxyphenyl)pyrimidin-4-yl)-1H-indole (1b). Yield: 45\%; white solid; m.p. 194-196 ${ }^{\circ} \mathrm{C}$; ${ }^{1} \mathrm{H}$ NMR (500 MHz, DMSO- $\left.d_{6}\right): \delta 11.90(\mathrm{~d}, J=8.4 \mathrm{~Hz}, 1 \mathrm{H})$, $8.66(\mathrm{~s}, 1 \mathrm{H}), 8.51-8.44(\mathrm{~m}, 1 \mathrm{H}), 7.74(\mathrm{dd}, J=5.5,3.0 \mathrm{~Hz}, 1 \mathrm{H}), 7.54-7.49(\mathrm{~m}, 1 \mathrm{H})$, $7.27(\mathrm{~d}, J=7.0 \mathrm{~Hz}, 1 \mathrm{H}), 7.13(\mathrm{dd}, J=8.4,3.4 \mathrm{~Hz}, 1 \mathrm{H}), 3.85(\mathrm{~d}, J=3.2 \mathrm{~Hz}, 1 \mathrm{H}) ;{ }^{13} \mathrm{C}$ NMR (125 MHz, DMSO-d $)$ : $\delta$ 163.49, 162.56, 161.76, 156.86, 137.71, 131.10, $129.95,129.71,125.69,122.75,122.14,121.39,114.47,113.89,113.81,112.66$, 55.75; HRMS: $m / z[\mathrm{M}+\mathrm{H}]^{+}$calcd for $\mathrm{C}_{19} \mathrm{H}_{15} \mathrm{ON}_{3}, 302.1288$; found, 302.1296 .

3-(2-(3-methoxyphenyl)pyrimidin-4-yl)-1H-indole (1c). Yield: 31\%; white 
solid; m.p. $188-190{ }^{\circ} \mathrm{C} ; \quad{ }^{1} \mathrm{H}$ NMR (500 MHz, DMSO- $\left.d 6\right): \delta 11.91(\mathrm{~s}, 1 \mathrm{H}), 8.71(\mathrm{~d}, J=$ $5.4 \mathrm{~Hz}, 1 \mathrm{H}), 8.68-8.63(\mathrm{~m}, 1 \mathrm{H}), 8.49(\mathrm{~d}, J=2.9 \mathrm{~Hz}, 1 \mathrm{H}), 8.12(\mathrm{~d}, J=7.7 \mathrm{~Hz}, 1 \mathrm{H})$, $8.08(\mathrm{~s}, 1 \mathrm{H}), 7.82$ (d, $J=5.4 \mathrm{~Hz}, 1 \mathrm{H}), 7.50(\mathrm{dd}, J=9.3,6.7 \mathrm{~Hz}, 2 \mathrm{H}), 7.26-7.20$ (m, 2H), $7.12(\mathrm{dd}, J=8.1,2.2 \mathrm{~Hz}, 1 \mathrm{H}), 3.89(\mathrm{~s}, 3 \mathrm{H}) ;{ }^{13} \mathrm{C}$ NMR (125 MHz, DMSO- $\left.d_{6}\right): \delta$ $163.38,162.67,160.00,156.94,140.06,137.72$, 130.23, 130.13, 125.68, 122.81, $122.08,121.42,120.46,116.90,114.64,113.69,112.98,112.72,55.56$; HRMS: $m / z$ $[\mathrm{M}+\mathrm{H}]^{+}$calcd for $\mathrm{C}_{19} \mathrm{H}_{15} \mathrm{ON}_{3}, 302.1288$; found, 302.1295 .

3-(2-(4-fluorophenyl)pyrimidin-4-yl)-1H-indole (1d). Yield: 40\%; white solid; m.p. 126-128 ${ }^{\circ} \mathrm{C}$; ${ }^{1} \mathrm{H}$ NMR (500 MHz, DMSO- $\left.d_{6}\right): \delta 11.94(\mathrm{~s}, 1 \mathrm{H}), 8.70$ (d, $J=5.4 \mathrm{~Hz}$, $1 \mathrm{H}), 8.62(\mathrm{dd}, J=6.4,2.2 \mathrm{~Hz}, 1 \mathrm{H}), 8.56(\mathrm{dd}, J=8.8,5.8 \mathrm{~Hz}, 2 \mathrm{H}), 8.49(\mathrm{~d}, J=2.3 \mathrm{~Hz}$, 1H), $7.81(\mathrm{~d}, J=5.4 \mathrm{~Hz}, 1 \mathrm{H}), 7.53-7.49(\mathrm{~m}, 1 \mathrm{H}), 7.41(\mathrm{t}, J=8.8 \mathrm{~Hz}, 2 \mathrm{H}), 7.24$ (pd, $J$ $=7.0,3.5 \mathrm{~Hz}, 2 \mathrm{H}) ;{ }^{13} \mathrm{C}$ NMR (125 MHz, DMSO- $\left.d_{6}\right): \delta 165.24,163.27,162.75$, $156.99,137.73,135.06,130.44,130.37,130.23,125.62,122.81,122.06,121.48$, 116.13, 115.96, 114.48, 113.65, 112.70; HRMS: $m / z[\mathrm{M}+\mathrm{H}]^{+}$calcd for $\mathrm{C}_{18} \mathrm{H}_{12} \mathrm{~N}_{3} \mathrm{~F}$, 290.1088; found, 290.1096.

3-(2-(3-fluorophenyl)pyrimidin-4-yl)-1 $\boldsymbol{H}$-indole (1e). Yield: 37\%; white solid; m.p. $128-130{ }^{\circ} \mathrm{C} ;{ }^{1} \mathrm{H}$ NMR (500 MHz, DMSO-d $)$ ): $\delta 11.95$ (s, $\left.1 \mathrm{H}\right), 8.73$ (d, $J=5.4 \mathrm{~Hz}$, $1 \mathrm{H}), 8.61(\mathrm{~d}, J=7.5 \mathrm{~Hz}, 1 \mathrm{H}), 8.51(\mathrm{~d}, J=2.9 \mathrm{~Hz}, 1 \mathrm{H}), 8.38$ (d, $J=7.8 \mathrm{~Hz}, 1 \mathrm{H}), 8.21$ (d, $J=9.8 \mathrm{~Hz}, 1 \mathrm{H}), 7.85(\mathrm{~d}, J=5.5 \mathrm{~Hz}, 1 \mathrm{H}), 7.64(\mathrm{dd}, J=14.1,7.9 \mathrm{~Hz}, 1 \mathrm{H}), 7.52(\mathrm{~d}$, $J=7.4 \mathrm{~Hz}, 1 \mathrm{H}), 7.39(\mathrm{td}, J=8.4,2.4 \mathrm{~Hz}, 1 \mathrm{H}), 7.29-7.23(\mathrm{~m}, 2 \mathrm{H}) ;{ }^{13} \mathrm{C}$ NMR $(125$ MHz, DMSO- $\left.d_{6}\right): \delta 163.97,162.82,162.43(\mathrm{~d}, J=3.2 \mathrm{~Hz}), 162.04,157.05,141.18(\mathrm{~d}$, $J=7.6 \mathrm{~Hz}), 137.75,131.23(\mathrm{~d}, J=8.1 \mathrm{~Hz}), 130.39,125.60,124.12(\mathrm{~d}, J=2.5 \mathrm{~Hz})$, $122.85,121.94,121.54,117.87,117.70,115.04,114.53,114.34,113.55,112.76$; HRMS: $m / z[\mathrm{M}+\mathrm{H}]^{+}$calcd for $\mathrm{C}_{18} \mathrm{H}_{12} \mathrm{~N}_{3} \mathrm{~F}, 290.1088$; found, 290.1096 .

3-(2-(p-tolyl)pyrimidin-4-yl)-1H-indole (1f). Yield: 36\%; white solid; m.p. 193-195 ${ }^{\circ} \mathrm{C} ;{ }^{1} \mathrm{H}$ NMR (500 MHz, DMSO-d 6$): \delta 11.90(\mathrm{~s}, 1 \mathrm{H}), 8.68(\mathrm{~d}, J=5.1 \mathrm{~Hz}, 1 \mathrm{H})$, $8.64(\mathrm{~d}, J=7.2 \mathrm{~Hz}, 1 \mathrm{H}), 8.45(\mathrm{~s}, 1 \mathrm{H}), 8.40(\mathrm{~d}, J=7.8 \mathrm{~Hz}, 2 \mathrm{H}), 7.77$ (d, $J=5.0 \mathrm{~Hz}$, $1 \mathrm{H}), 7.51(\mathrm{~d}, J=7.6 \mathrm{~Hz}, 1 \mathrm{H}), 7.38$ (d, $J=7.5 \mathrm{~Hz}, 2 \mathrm{H}), 7.28-7.21(\mathrm{~m}, 2 \mathrm{H}), 2.39$ (s, $3 \mathrm{H}) ;{ }^{13} \mathrm{C}$ NMR (125 MHz, DMSO-d $): \delta 163.71,162.60,156.93,140.72,137.70$, $135.89,129.96,129.75,128.08,125.64,122.80,122.09,121.46,114.28,113.78$, 
112.69, 21.48; HRMS: $m / z[\mathrm{M}+\mathrm{H}]^{+}$calcd for $\mathrm{C}_{19} \mathrm{H}_{15} \mathrm{~N}_{3}$, 286.1339; found, 286.1346. 3-(2-(m-tolyl)pyrimidin-4-yl)-1H-indole (1g). Yield: 47\%; white solid; m.p. 121-123 ${ }^{\circ} \mathrm{C} ;{ }^{1} \mathrm{H}$ NMR (500 MHz, DMSO-d $): \delta 11.92(\mathrm{~s}, 1 \mathrm{H}), 8.71(\mathrm{~d}, J=5.4 \mathrm{~Hz}, 1 \mathrm{H})$, $8.66(\mathrm{~d}, J=7.5 \mathrm{~Hz}, 1 \mathrm{H}), 8.48(\mathrm{~d}, J=2.5 \mathrm{~Hz}, 1 \mathrm{H}), 8.34(\mathrm{~d}, J=8.1 \mathrm{~Hz}, 2 \mathrm{H}), 7.81(\mathrm{~d}, J$ $=5.4 \mathrm{~Hz}, 1 \mathrm{H}), 7.52(\mathrm{~d}, J=7.9 \mathrm{~Hz}, 1 \mathrm{H}), 7.47$ (t, $J=7.5 \mathrm{~Hz}, 1 \mathrm{H}), 7.36(\mathrm{~d}, J=7.3 \mathrm{~Hz}$, 1H), $7.25(\mathrm{dd}, J=14.6,7.3 \mathrm{~Hz}, 2 \mathrm{H}), 2.45$ (s, 3H); ${ }^{13} \mathrm{C}$ NMR (125 MHz, DMSO- $\left.d_{6}\right): \delta$ $163.73,162.63,156.94,138.56,138.14,137.73,131.58,130.06,129.02,128.74$, $125.67,125.31,122.77,122.08,121.44,114.50,113.79,112.70,21.71$; HRMS: $m / z$ $[\mathrm{M}+\mathrm{H}]^{+}$calcd for $\mathrm{C}_{19} \mathrm{H}_{15} \mathrm{~N}_{3}, 286.1339$; found, 286.1347.

5-bromo-3-(2-phenylpyrimidin-4-yl)-1H-indole (3a). Yield: 28\%; white solid; m.p. 201-203 ${ }^{\circ} \mathrm{C} ;{ }^{1} \mathrm{H}$ NMR (500 MHz, DMSO- $\left.d_{6}\right): \delta 12.11(\mathrm{~s}, 1 \mathrm{H}), 8.86(\mathrm{~d}, J=2.0 \mathrm{~Hz}$, $1 \mathrm{H}), 8.75(\mathrm{~d}, J=5.4 \mathrm{~Hz}, 1 \mathrm{H}), 8.55(\mathrm{~d}, J=3.0 \mathrm{~Hz}, 1 \mathrm{H}), 8.50-8.46(\mathrm{~m}, 2 \mathrm{H}), 7.83(\mathrm{~d}, J$ $=5.4 \mathrm{~Hz}, 1 \mathrm{H}), 7.58(\mathrm{tdd}, J=6.8,3.8,1.7 \mathrm{~Hz}, 3 \mathrm{H}), 7.49(\mathrm{~d}, J=8.6 \mathrm{~Hz}, 1 \mathrm{H}), 7.37(\mathrm{dd}$, $J=8.6,2.0 \mathrm{~Hz}, 1 \mathrm{H}) ;{ }^{13} \mathrm{C} \mathrm{NMR}\left(125 \mathrm{MHz}, \mathrm{DMSO}-d_{6}\right): \delta 163.68,162.17,157.25$, 138.52, 136.40, 131.39, 131.11, 129.14, 127.99, 127.43, 125.31, 124.51, 114.71, 114.61, 114.07, 113.30; HRMS: $m / z[\mathrm{M}+\mathrm{H}]^{+}$calcd for $\mathrm{C}_{18} \mathrm{H}_{12} \mathrm{~N}_{3} \mathrm{Br}, 350.0287$; found, 350.0287 .

5-bromo-3-(2-(4-methoxyphenyl)pyrimidin-4-yl)-1H-indole (3b). Yield: 48\%; pale yellow solid; m.p. 97-99 ${ }^{\circ} \mathrm{C}$; ${ }^{1} \mathrm{H}$ NMR (500 MHz, DMSO- $\left.d_{6}\right): \delta 12.08$ (s, 1H), $8.84(\mathrm{~s}, 1 \mathrm{H}), 8.68(\mathrm{~d}, J=5.4 \mathrm{~Hz}, 1 \mathrm{H}), 8.51(\mathrm{~s}, 1 \mathrm{H}), 8.43(\mathrm{~d}, J=8.7 \mathrm{~Hz}, 2 \mathrm{H}), 7.75$ (d, $J$ $=5.4 \mathrm{~Hz}, 1 \mathrm{H}), 7.49(\mathrm{~d}, J=8.6 \mathrm{~Hz}, 1 \mathrm{H}), 7.36(\mathrm{dd}, J=8.6,1.6 \mathrm{~Hz}, 1 \mathrm{H}), 7.12(\mathrm{~d}, J=8.8$ $\mathrm{Hz}, 2 \mathrm{H}), 3.86(\mathrm{~s}, 3 \mathrm{H})$; ${ }^{13} \mathrm{C} \mathrm{NMR}\left(125 \mathrm{MHz}, \mathrm{DMSO}-d_{6}\right): \delta 163.52,162.01,161.85$, $157.13,136.37,131.23,130.99,129.59,127.42,125.26,124.49,114.68,114.49$, 114.00, 113.89, 113.41, 55.82; HRMS calcd for $\mathrm{C}_{19} \mathrm{H}_{14} \mathrm{~N}_{3}{ }^{81} \mathrm{Br}[\mathrm{M}+\mathrm{H}]^{+}$382.0373, found: 382.0382 。

5-bromo-3-(2-(3-methoxyphenyl)pyrimidin-4-yl)-1H-indole (3c). Yield: 55\%; white solid; m.p. 192-194 ${ }^{\circ} \mathrm{C}$; ${ }^{1} \mathrm{H}$ NMR (500 MHz, DMSO-d $): \delta 12.11$ (s, 1H), 8.91 (s, 1H), $8.73(\mathrm{~d}, J=5.4 \mathrm{~Hz}, 1 \mathrm{H}), 8.55(\mathrm{~d}, J=2.9 \mathrm{~Hz}, 1 \mathrm{H}), 8.08(\mathrm{dd}, J=10.7,4.5 \mathrm{~Hz}$, 2H), $7.83(\mathrm{~d}, J=5.4 \mathrm{~Hz}, 1 \mathrm{H}), 7.52-7.45(\mathrm{~m}, 2 \mathrm{H}), 7.37$ (dd, $J=8.6,1.7 \mathrm{~Hz}, 1 \mathrm{H}), 7.12$ 
(dd, $J=8.1,2.4 \mathrm{~Hz}, 1 \mathrm{H}), 3.95$ (s, 3H); ${ }^{13} \mathrm{C}$ NMR (125 MHz, DMSO- $\left.d_{6}\right): \delta 163.42$, $162.18,160.04,157.14,139.95,136.40,131.44,130.20,127.45,125.33,124.58$, $120.45,117.82,114.72,114.64,114.07,113.23,112.01,55.67$; HRMS calcd for $\mathrm{C}_{19} \mathrm{H}_{14} \mathrm{~N}_{3}{ }^{81} \mathrm{Br}[\mathrm{M}+\mathrm{H}]^{+}$382.0373, found: 382.0382 。

5-bromo-3-(2-(4-fluorophenyl)pyrimidin-4-yl)-1 $\boldsymbol{H}$-indole (3d). Yield: 50\%; white solid; m.p. 88-90 ${ }^{\circ} \mathrm{C}$; ${ }^{1} \mathrm{H}$ NMR (500 MHz, DMSO- $\left.d_{6}\right): \delta 12.13(\mathrm{~s}, 1 \mathrm{H}), 8.79(\mathrm{~d}$, $J=1.2 \mathrm{~Hz}, 1 \mathrm{H}), 8.73(\mathrm{~d}, J=5.4 \mathrm{~Hz}, 1 \mathrm{H}), 8.55(\mathrm{~d}, J=2.8 \mathrm{~Hz}, 1 \mathrm{H}), 8.51(\mathrm{dd}, J=8.5$, $5.9 \mathrm{~Hz}, 2 \mathrm{H}), 7.82$ (d, $J=5.4 \mathrm{~Hz}, 1 \mathrm{H}), 7.49$ (d, $J=8.6 \mathrm{~Hz}, 1 \mathrm{H}), 7.44-7.34$ (m, 3H); ${ }^{13} \mathrm{C}$ NMR (125 MHz, DMSO- $\left.d_{6}\right): \delta$ 165.29, 163.32, 162.80, 162.18, 157.28, 136.41, $135.03,131.48,130.27,127.35,125.33,124.34,116.17,116.00,114.74,114.56$, 114.09, 113.23; HRMS: $m / z[\mathrm{M}+\mathrm{H}]^{+}$calcd for $\mathrm{C}_{18} \mathrm{H}_{11} \mathrm{~N}_{3} \mathrm{BrF}, 368.0193$; found, 368.0189 .

5-bromo-3-(2-(3-fluorophenyl)pyrimidin-4-yl)-1H-indole (3e). Yield: 43\%; white solid; m.p. 205-206 ${ }^{\circ} \mathrm{C}$; ${ }^{1} \mathrm{H}$ NMR (500 MHz, DMSO- $\left.d_{6}\right): \delta 12.13$ (s, 1H), 8.81 (s, 1H), $8.74(\mathrm{~d}, J=5.4 \mathrm{~Hz}, 1 \mathrm{H}), 8.55(\mathrm{~d}, J=2.8 \mathrm{~Hz}, 1 \mathrm{H}), 8.31(\mathrm{~d}, J=7.8 \mathrm{~Hz}, 1 \mathrm{H})$, $8.17(\mathrm{~d}, J=10.3 \mathrm{~Hz}, 1 \mathrm{H}), 7.85(\mathrm{~d}, J=5.4 \mathrm{~Hz}, 1 \mathrm{H}), 7.62(\mathrm{dd}, J=14.1,7.8 \mathrm{~Hz}, 1 \mathrm{H})$, $7.49(\mathrm{~d}, J=8.6 \mathrm{~Hz}, 1 \mathrm{H}), 7.43-7.33(\mathrm{~m}, 2 \mathrm{H}) ;{ }^{13} \mathrm{C}$ NMR $\left(125 \mathrm{MHz}, \mathrm{DMSO}-d_{6}\right): \delta$ 163.98, 162.45, 162.25, 162.05, 157.27, 141.09 (d, $J=7.6 \mathrm{~Hz}), 136.41,131.59$, $131.18(\mathrm{~d}, J=8.1 \mathrm{~Hz}), 127.36,125.34,124.42,123.97$ (d, $J=2.3 \mathrm{~Hz}), 117.95,117.78$, 115.06, 114.73, 114.51, 114.32, 114.14, 113.13; HRMS: $m / z[\mathrm{M}+\mathrm{H}]^{+}$calcd for $\mathrm{C}_{18} \mathrm{H}_{11} \mathrm{~N}_{3} \mathrm{BrF}, 368.0193$; found, 368.0198 .

5-bromo-3-(2-(p-tolyl)pyrimidin-4-yl)-1H-indole (3f). Yield: 38\%; pale yellow solid; m.p. 197-199 ${ }^{\circ} \mathrm{C}$; ${ }^{1} \mathrm{H}$ NMR (500 MHz, DMSO-d6): $\delta 12.09$ (s, 1H), 8.86 (d, $J=$ $1.7 \mathrm{~Hz}, 1 \mathrm{H}), 8.71(\mathrm{~d}, J=5.4 \mathrm{~Hz}, 1 \mathrm{H}), 8.53(\mathrm{~s}, 1 \mathrm{H}), 8.37$ (d, $J=8.1 \mathrm{~Hz}, 2 \mathrm{H}), 7.79(\mathrm{~d}, J$ $=5.4 \mathrm{~Hz}, 1 \mathrm{H}), 7.49(\mathrm{~d}, J=8.6 \mathrm{~Hz}, 1 \mathrm{H}), 7.41-7.35(\mathrm{~m}, 3 \mathrm{H}), 2.41(\mathrm{~s}, 3 \mathrm{H}) ;{ }^{13} \mathrm{C} \mathrm{NMR}$ (125 MHz, DMSO-d6): $\delta$ 163.75, 162.07, 157.19, 140.89, 136.38, 135.85, 131.27, $129.75,127.97,127.44,125.27,124.55,114.69,114.32,114.03,113.35,21.44$; HRMS: $m / z[\mathrm{M}+\mathrm{H}]^{+}$calcd for $\mathrm{C}_{19} \mathrm{H}_{14} \mathrm{~N}_{3} \mathrm{Br}$, 364.0444; found, 368.0444.

5-bromo-3-(2-(m-tolyl)pyrimidin-4-yl)-1H-indole (3g). Yield: 42\%; pale 
yellow solid; m.p. $167-169{ }^{\circ} \mathrm{C}$; ${ }^{1} \mathrm{H}$ NMR (500 MHz, DMSO- $\left.d_{6}\right): \delta 12.09$ (s, 1H), 8.94 (s, 1H), $8.73(\mathrm{~d}, J=5.4 \mathrm{~Hz}, 1 \mathrm{H}), 8.54(\mathrm{~d}, J=2.8 \mathrm{~Hz}, 1 \mathrm{H}), 8.35(\mathrm{~s}, 1 \mathrm{H}), 8.27$ (d, $J=$ $7.7 \mathrm{~Hz}, 1 \mathrm{H}), 7.81$ (d, $J=5.4 \mathrm{~Hz}, 1 \mathrm{H}), 7.51-7.44$ (m, 2H), $7.40-7.35$ (m, 2H), 2.47 (s, 3H); ${ }^{13} \mathrm{C}$ NMR (125 MHz, DMSO- $\left.d_{6}\right): \delta 163.68,162.08,157.19,138.44,138.21$, 136.37 , 131.68, 131.32, 129.06, 128.73, 127.50, 125.25, 125.18, 124.75, 114.69, 114.45, 114.05, 113.30, 21.68; HRMS: $m / z[\mathrm{M}+\mathrm{H}]^{+}$calcd for $\mathrm{C}_{19} \mathrm{H}_{14} \mathrm{~N}_{3} \mathrm{Br}, 364.0444$; found, 368.0446 .

6-bromo-3-(2-phenylpyrimidin-4-yl)-1H-indole (4a). Yield: 41\%; pale yellow solid; m.p. $175-177^{\circ} \mathrm{C}$; ${ }^{1} \mathrm{H}$ NMR (500 MHz, DMSO-d $): \delta 12.03$ (s, 1H), 8.74 (d, $J=$ $5.4 \mathrm{~Hz}, 1 \mathrm{H}), 8.60(\mathrm{~d}, J=8.5 \mathrm{~Hz}, 1 \mathrm{H}), 8.51(\mathrm{t}, J=4.4 \mathrm{~Hz}, 3 \mathrm{H}), 7.82(\mathrm{~d}, J=5.4 \mathrm{~Hz}$, $1 \mathrm{H}), 7.70(\mathrm{~d}, J=1.5 \mathrm{~Hz}, 1 \mathrm{H}), 7.60-7.53(\mathrm{~m}, 3 \mathrm{H}), 7.40(\mathrm{dd}, J=8.5,1.6 \mathrm{~Hz}, 1 \mathrm{H}) ;{ }^{13} \mathrm{C}$ NMR (125 MHz, DMSO-d6): $\delta$ 163.68, 162.26, 157.16, 138.58, 138.40, 131.05, $130.98,129.15,128.13,124.70,124.37,123.85,115.46,115.27,114.66,113.90$; HRMS: $m / z[\mathrm{M}+\mathrm{H}]^{+}$calcd for $\mathrm{C}_{18} \mathrm{H}_{13} \mathrm{~N}_{3} \mathrm{Br}, 350.0287$; found, 350.0288 .

6-bromo-3-(2-(4-methoxyphenyl)pyrimidin-4-yl)-1H-indole (4b). Yield: 42\%; white solid; m.p. $>210{ }^{\circ} \mathrm{C}$; ${ }^{1} \mathrm{H}$ NMR (500 MHz, DMSO- $\left.d_{6}\right): \delta 12.00$ (s, 1H), 8.68 (d, $J$ $=5.4 \mathrm{~Hz}, 1 \mathrm{H}), 8.58(\mathrm{~d}, J=8.5 \mathrm{~Hz}, 1 \mathrm{H}), 8.47(\mathrm{dd}, J=13.9,5.7 \mathrm{~Hz}, 3 \mathrm{H}), 7.74(\mathrm{~d}, J=$ $5.4 \mathrm{~Hz}, 1 \mathrm{H}), 7.69$ (s, 1H), $7.38(\mathrm{~d}, J=8.5 \mathrm{~Hz}, 1 \mathrm{H}), 7.11(\mathrm{~d}, J=8.7 \mathrm{~Hz}, 2 \mathrm{H}), 3.85$ (s, $3 \mathrm{H}) ;{ }^{13} \mathrm{C}$ NMR $\left(125 \mathrm{MHz}, \mathrm{DMSO}-d_{6}\right): \delta 163.54,162.08,161.80,157.07,138.56$, $130.93,130.79,129.75,124.71,124.27,123.85,115.41,115.25,114.49,114.00$, 113.92, 55.76; HRMS calcd for $\mathrm{C}_{19} \mathrm{H}_{14} \mathrm{ON}_{3}{ }^{81} \mathrm{Br}[\mathrm{M}+\mathrm{H}]^{+}$382.0373, found: 382.0384 。

6-bromo-3-(2-(3-methoxyphenyl)pyrimidin-4-yl)-1H-indole (4c). Yield: 53\%; yellow solid; m.p. $180-181{ }^{\circ} \mathrm{C}$; ${ }^{1} \mathrm{H}$ NMR (500 MHz, DMSO- $\left.d_{6}\right): \delta 12.03$ (s, 1H), 8.74 $(\mathrm{d}, J=5.4 \mathrm{~Hz}, 1 \mathrm{H}), 8.60$ (d, $J=8.5 \mathrm{~Hz}, 1 \mathrm{H}), 8.51$ (d, $J=2.8 \mathrm{~Hz}, 1 \mathrm{H}), 8.09$ (d, $J=7.7$ $\mathrm{Hz}, 1 \mathrm{H}), 8.05$ (s, 1H), $7.82(\mathrm{~d}, J=5.4 \mathrm{~Hz}, 1 \mathrm{H}), 7.70(\mathrm{~s}, 1 \mathrm{H}), 7.49$ (t, $J=7.9 \mathrm{~Hz}, 1 \mathrm{H})$, $7.40(\mathrm{~d}, J=8.5 \mathrm{~Hz}, 1 \mathrm{H}), 7.12(\mathrm{dd}, J=8.1,1.6 \mathrm{~Hz}, 1 \mathrm{H}), 3.89(\mathrm{~s}, 3 \mathrm{H}) ;{ }^{13} \mathrm{C}$ NMR $(125$ MHz, DMSO- $\left.d_{6}\right): \delta 163.45,162.20,160.00,157.16,139.90,138.58,130.96,130.26$, $124.71,124.30,123.76,120.49,117.11,115.47,115.31,114.75,113.85,112.83$, 
55.58; HRMS calcd for $\mathrm{C}_{19} \mathrm{H}_{14} \mathrm{ON}_{3}{ }^{81} \mathrm{Br}[\mathrm{M}+\mathrm{H}]^{+}$382.0373, found: 380.0377 。

6-bromo-3-(2-(4-fluorophenyl)pyrimidin-4-yl)-1 $\boldsymbol{H}$-indole (4d). Yield: 32\%; white solid; m.p. 187-188 ${ }^{\circ} \mathrm{C}$; ${ }^{1} \mathrm{H}$ NMR (500 MHz, DMSO-d $): \delta 12.04$ (s, 1H), 8.73 $(\mathrm{d}, J=5.4 \mathrm{~Hz}, 1 \mathrm{H}), 8.59-8.52(\mathrm{~m}, 3 \mathrm{H}), 8.52(\mathrm{~d}, J=2.9 \mathrm{~Hz}, 1 \mathrm{H}), 7.82(\mathrm{~d}, J=5.4 \mathrm{~Hz}$, $1 \mathrm{H}), 7.70(\mathrm{~d}, J=1.7 \mathrm{~Hz}, 1 \mathrm{H}), 7.43-7.36(\mathrm{~m}, 3 \mathrm{H}) ;{ }^{13} \mathrm{C}$ NMR $\left(125 \mathrm{MHz}, \mathrm{DMSO}-d_{6}\right)$ : $\delta 165.27,163.30,162.81,162.27,157.22,138.59,130.46(\mathrm{~d}, J=8.7 \mathrm{~Hz}), 131.06$, $130.50,130.43,124.65,124.37,123.79,116.16,115.99,115.46,115.29,114.59$, 113.83; HRMS: $m / z[\mathrm{M}+\mathrm{H}]^{+}$calcd for $\mathrm{C}_{18} \mathrm{H}_{13} \mathrm{~N}_{3} \mathrm{Br}, 368.0193$; found, 368.0193.

6-bromo-3-(2-(3-fluorophenyl)pyrimidin-4-yl)-1 $H$-indole (4e). Yield: 61\%; white solid; m.p. $>210{ }^{\circ} \mathrm{C} ;{ }^{1} \mathrm{H}$ NMR (500 MHz, DMSO-d $): \delta 12.06(\mathrm{~s}, 1 \mathrm{H}), 8.76(\mathrm{~d}, J$ $=5.4 \mathrm{~Hz}, 1 \mathrm{H}), 8.57-8.52(\mathrm{~m}, 2 \mathrm{H}), 8.35(\mathrm{~d}, J=7.8 \mathrm{~Hz}, 1 \mathrm{H}), 8.17(\mathrm{~d}, J=10.1 \mathrm{~Hz}, 1 \mathrm{H})$, $7.86(\mathrm{~d}, J=5.4 \mathrm{~Hz}, 1 \mathrm{H}), 7.70(\mathrm{~d}, J=1.5 \mathrm{~Hz}, 1 \mathrm{H}), 7.63(\mathrm{dd}, J=14.1,7.9 \mathrm{~Hz}, 1 \mathrm{H})$, $7.41(\mathrm{dd}, J=8.5,1.7 \mathrm{~Hz}, 2 \mathrm{H}) ;{ }^{13} \mathrm{C}$ NMR (125 MHz, DMSO- $\left.d_{6}\right): \delta 163.96,162.50(\mathrm{~d}, J$ $=3.2 \mathrm{~Hz}), 162.35,162.03,157.28,138.60,131.26,130.77,127.17,124.62$, 124.44, $124.18,123.66,115.50,115.33,115.16,114.55,114.37,113.72 ;$ HRMS: $m / z[\mathrm{M}+\mathrm{H}]$ calcd for $\mathrm{C}_{18} \mathrm{H}_{11} \mathrm{~N}_{3} \mathrm{BrF}, 368.0193$; found, 368.0192.

6-bromo-3-(2-(p-tolyl)pyrimidin-4-yl)-1H-indole (4f). Yield: 37\%; yellow solid; m.p. 192-194 ${ }^{\circ} \mathrm{C} ;{ }^{1} \mathrm{H}$ NMR (500 MHz, DMSO-d $): \delta 12.02$ (s, $\left.1 \mathrm{H}\right), 8.71$ (d, $J=5.4 \mathrm{~Hz}$, 1H), 8.59 (d, $J=8.5 \mathrm{~Hz}, 1 \mathrm{H}), 8.49$ (d, $J=2.8 \mathrm{~Hz}, 1 \mathrm{H}), 8.39$ (d, $J=8.0 \mathrm{~Hz}, 2 \mathrm{H}), 7.78$ $(\mathrm{d}, J=5.4 \mathrm{~Hz}, 1 \mathrm{H}), 7.70(\mathrm{~d}, J=1.1 \mathrm{~Hz}, 1 \mathrm{H}), 7.39(\mathrm{dd}, J=13.5,4.7 \mathrm{~Hz}, 3 \mathrm{H}), 2.40$ (s, $3 \mathrm{H}) ;{ }^{13} \mathrm{C}$ NMR (125 MHz, DMSO-d6): $\delta 163.75,162.16,157.09,140.78,138.57$, $135.75,130.87,129.76,128.11,124.71,124.31,123.84,115.43,115.26,114.38$, 113.95, 21.49; HRMS: $m / z[\mathrm{M}+\mathrm{H}]^{+}$calcd for $\mathrm{C}_{19} \mathrm{H}_{14} \mathrm{~N}_{3} \mathrm{Br}, 364.0444$; found, 364.0443.

6-bromo-3-(2-(m-tolyl)pyrimidin-4-yl)-1H-indole (4g). Yield: 59\%; pale yellow solid; m.p. 203-204 ${ }^{\circ} \mathrm{C}$; ${ }^{1} \mathrm{H}$ NMR (500 MHz, DMSO- $\left.d_{6}\right): \delta 12.02$ (s, 1H), 8.73 (d, $J=5.4 \mathrm{~Hz}, 1 \mathrm{H}), 8.59$ (d, $J=8.5 \mathrm{~Hz}, 1 \mathrm{H}), 8.50$ (d, $J=2.7 \mathrm{~Hz}, 1 \mathrm{H}), 8.30$ (d, $J=9.2$ $\mathrm{Hz}, 2 \mathrm{H}), 7.81(\mathrm{~d}, J=5.4 \mathrm{~Hz}, 1 \mathrm{H}), 7.70(\mathrm{~d}, J=1.1 \mathrm{~Hz}, 1 \mathrm{H}), 7.46(\mathrm{t}, J=7.5 \mathrm{~Hz}, 1 \mathrm{H})$, $7.41(\mathrm{dd}, J=8.5,1.3 \mathrm{~Hz}, 1 \mathrm{H}), 7.36(\mathrm{~d}, J=7.5 \mathrm{~Hz}, 1 \mathrm{H}), 2.45(\mathrm{~s}, 3 \mathrm{H}) ;{ }^{13} \mathrm{C} \mathrm{NMR}(125$ MHz, DMSO-d6): $\delta 163.78,162.15,157.17,138.57,138.40,138.21,131.67,130.89$, 
$129.07,128.73,125.32,124.70,124.34,123.80,115.44,115.27,114.60,113.93$, 21.69; HRMS: $m / z[\mathrm{M}+\mathrm{H}]^{+}$calcd for $\mathrm{C}_{19} \mathrm{H}_{14} \mathrm{~N}_{3} \mathrm{Br}, 364.0444$; found, 364.0443 .

\subsubsection{General procedure for synthesis of $\mathbf{2} \mathbf{a} \sim \mathbf{g}$ meridianin analogs.}

To a stirring solution of 4-hydroxyindole (12) in dry DMF $(10 \mathrm{~mL})$ was added sodium hydride (5.0 equiv.) at $0^{\circ} \mathrm{C}$ and the mixture was stirred for $30 \mathrm{~min}$. Then, the p-toluenesulfonyl (3.0 equiv.) was added. After stirring for $4 \mathrm{~h}$ at room temperature. The reaction was quenched with saturated $\mathrm{NaHCO}_{3}$ solution and extracted with ethyl acetate. $(3 \times 50 \mathrm{~mL})$. The combined organic layers were washed with brine and dried over magnesium sulfate anhydrous. After filtration, the solvent was removed under vacuum and the residue was purified by silica gel column chromatography (petroleum ether/ethyl acetate 10:1) to give compound $\mathbf{1 3}$.

1-tosyl-1H-indol-4-yl 4-methylbenzenesulfonate (13). Yield: 85\%; pale yellow solid; m.p. $100-102^{\circ} \mathrm{C}$; ${ }^{1} \mathrm{H}$ NMR (400 MHz, DMSO- $\left.d_{6}\right): \delta 7.89(\mathrm{~d}, J=8.5 \mathrm{~Hz}, 1 \mathrm{H})$, $7.88(\mathrm{~d}, J=3.4 \mathrm{~Hz}, 1 \mathrm{H}), 7.85$ (s, 1H), 7.78 (t, $J=4.1 \mathrm{~Hz}, 1 \mathrm{H}), 7.71(\mathrm{~s}, 1 \mathrm{H}), 7.69$ (s, 1H), $7.38(\mathrm{dd}, J=15.4,7.3 \mathrm{~Hz}, 4 \mathrm{H}), 7.32$ (d, $J=8.2 \mathrm{~Hz}, 1 \mathrm{H}), 6.93(\mathrm{~d}, J=8.0 \mathrm{~Hz}, 1 \mathrm{H})$, $6.51(\mathrm{~d}, J=3.7 \mathrm{~Hz}, 1 \mathrm{H}), 2.38(\mathrm{~s}, 3 \mathrm{H}), 2.33(\mathrm{~s}, 3 \mathrm{H}) ;{ }^{13} \mathrm{C}$ NMR (100 MHz, DMSO-d6): $\delta 146.42,146.38,141.98,135.99,134.31,131.72,130.84,130.62,128.71,128.33$, 127.28, 125.88, 124.78, 117.02, 112.81, 105.63, 21.62, 21.52; HRMS: $m / z[\mathrm{M}+\mathrm{H}]^{+}$ calcd for $\mathrm{C}_{22} \mathrm{H}_{20} \mathrm{O}_{5} \mathrm{NS}_{2}, 442.0777$; found, 442.0789 .

To a stirring solution of acetic anhydride ( 2.0 equiv.) in dry dichloromethane ( 8 $\mathrm{mL}$ ) was added aluminium chloride (5.0 equiv.) at $0^{\circ} \mathrm{C}$. Then, compound $\mathbf{1 3}$ in dry dichloromethane $(8 \mathrm{~mL})$ was added dropwise and the mixture was stirred for $2 \mathrm{~h}$ at room temperature. The reaction was quenched with saturated aqueous $\mathrm{NH}_{4} \mathrm{Cl}$ and extracted with ethyl acetate $(3 \times 50 \mathrm{~mL})$. The combined organic layers were washed with brine and dried over magnesium sulfate anhydrous. After filtration, the solvent was removed under vacuum and the residue was purified by silica gel column chromatography (petroleum ether/ethyl acetate 8:1) to give compound $\mathbf{1 4}$.

3-acetyl-1-tosyl-1H-indol-4-yl 4-methylbenzenesulfonate (14). Yield: 70\%; 
pale yellow solid; m.p. $163-165{ }^{\circ} \mathrm{C}$; ${ }^{1} \mathrm{H}$ NMR (400 MHz, DMSO- $\left.d_{6}\right): \delta 8.66(\mathrm{~s}, 1 \mathrm{H})$, $8.04(\mathrm{~s}, 1 \mathrm{H}), 8.02(\mathrm{~s}, 1 \mathrm{H}), 7.95(\mathrm{~d}, J=7.9 \mathrm{~Hz}, 1 \mathrm{H}), 7.52(\mathrm{~s}, 1 \mathrm{H}), 7.50(\mathrm{~s}, 1 \mathrm{H}), 7.47$ (s, 1H), 7.45 (s, 1H), 7.39 (t, J=8.2 Hz, 1H), 7.34 (s, 1H), 7.32 (s, 1H), 6.90-6.85 (m, 1H), $2.48(\mathrm{~s}, 3 \mathrm{H}), 2.38(\mathrm{~s}, 3 \mathrm{H}), 2.36(\mathrm{~s}, 3 \mathrm{H}) ;{ }^{13} \mathrm{C}$ NMR (100 MHz, DMSO- $\left.d_{6}\right): \delta$ 192.02 , 147.08, 146.02, 142.26, 136.52, 134.25, 133.66, 131.87, 131.07, 130.27, $128.79,128.67,127.81,126.84,126.70,122.26,120.73,119.30,112.91,105.45$, 64.26, 29.61, 21.60; HRMS: $m / z[\mathrm{M}+\mathrm{H}]^{+}$calcd for $\mathrm{C}_{24} \mathrm{H}_{22} \mathrm{O}_{6} \mathrm{NS}_{2}, 484.0883$; found, 484.0891 .

To a solution of compound 14 in DMF (5 mL) was added DMF-DMA (1.5 equiv.). The reaction mixture was stirred at $110^{\circ} \mathrm{C}$ for $5 \mathrm{~h}$ under a nitrogen atmosphere. Then, the mixture was poured into ice water and extracted with ethyl acetate $(3 \times 50 \mathrm{~mL})$. The combined organic layers were washed with brine and dried over magnesium sulfate anhydrous. After filtration, the solvent was removed under vacuum and the residue was purified by silica gel column chromatography (petroleum ether/ethyl acetate $2: 1)$ to give intermediate $\mathbf{1 5 .}$

\section{(E)-3-(3-(dimethylamino)acryloyl)-1-tosyl-1 $H$-indol-4-yl}

4-methylbenzenesulfonate (15). Yield: 64\%; pale yellow solid; m.p. 129-131 ${ }^{\circ} \mathrm{C}$; ${ }^{1} \mathrm{H}$ NMR (400 MHz, DMSO-d $\left.d_{6}\right): \delta 8.09(\mathrm{~s}, 1 \mathrm{H}), 7.97$ (s, 1H), 7.95 (d, $J=2.0 \mathrm{~Hz}, 2 \mathrm{H}$ ), $7.93(\mathrm{~s}, 1 \mathrm{H}), 7.60(\mathrm{~s}, 1 \mathrm{H}), 7.58(\mathrm{~s}, 1 \mathrm{H}), 7.43(\mathrm{~s}, 2 \mathrm{H}), 7.41(\mathrm{~s}, 1 \mathrm{H}), 7.36(\mathrm{~d}, J=8.2 \mathrm{~Hz}$, 1H), $7.33(\mathrm{~s}, 1 \mathrm{H}), 7.31(\mathrm{~s}, 1 \mathrm{H}), 7.01(\mathrm{~d}, J=8.0 \mathrm{~Hz}, 1 \mathrm{H}), 5.40(\mathrm{~d}, J=12.5 \mathrm{~Hz}, 1 \mathrm{H})$, $3.09(\mathrm{~d}, J=24.6 \mathrm{~Hz}, 3 \mathrm{H}), 2.81$ (d, $J=16.5 \mathrm{~Hz}, 3 \mathrm{H}), 2.37$ (s, 3H), 2.34 (d, $J=6.3 \mathrm{~Hz}$, $3 \mathrm{H}) ;{ }^{13} \mathrm{C}$ NMR (100 MHz, DMSO- $\left.d_{6}\right): \delta 170.81,162.77,154.45,146.69,145.76$, $142.23,136.55,134.01,132.10,130.94,130.23$, 129.12, 128.76, 127.58, 126.13, $121.74,118.13,112.70,60.22$, 45.73, 37.16, 36.24, 36.24, 31.23, 21.58, 21.22, 14.54; HRMS: $m / z[\mathrm{M}+\mathrm{H}]^{+}$calcd for $\mathrm{C}_{27} \mathrm{H}_{27} \mathrm{O}_{6} \mathrm{~N}_{2} \mathrm{~S}_{2}, 539.1305$; found, 539.1316 .

To a solution of intermediate $\mathbf{1 5}$ in 2-methoxyethanol $(5 \mathrm{~mL})$ were added $\mathbf{5} \sim \mathbf{1 1}$ (2.5 equiv.) and potassium carbonate (2.0 equiv.) respectively. The reaction mixture was stirred at $120^{\circ} \mathrm{C}$ for $20 \mathrm{~h}$ under a nitrogen atmosphere. Then, the mixture was poured into ice water and extracted with ethyl acetate $(3 \times 50 \mathrm{~mL})$. The combined organic layers were washed with brine and dried over magnesium sulfate anhydrous. 
After filtration, the solvent was removed under vacuum and the residue was purified by silica gel column chromatography (petroleum ether/ethyl acetate 10:1) to give get the final target compounds $2 \mathbf{a}-\mathrm{g}$.

3-(2-phenylpyrimidin-4-yl)-1H-indol-4-ol (2a). Yield: 46\%; pale yellow solid solid; m.p. 195-197 ${ }^{\circ} \mathrm{C}$; ${ }^{1} \mathrm{H}$ NMR (500 MHz, DMSO- $\left.d_{6}\right): \delta 13.44(\mathrm{~s}, 1 \mathrm{H}), 12.07$ (s, $1 \mathrm{H}), 8.74(\mathrm{~d}, J=5.6 \mathrm{~Hz}, 1 \mathrm{H}), 8.53(\mathrm{~s}, 1 \mathrm{H}), 8.23(\mathrm{dd}, J=6.7,1.7 \mathrm{~Hz}, 2 \mathrm{H}), 8.00(\mathrm{~d}, J=$ $5.6 \mathrm{~Hz}, 1 \mathrm{H}), 7.61(\mathrm{dd}, J=9.7,4.9 \mathrm{~Hz}, 3 \mathrm{H}), 7.06(\mathrm{t}, J=7.9 \mathrm{~Hz}, 1 \mathrm{H}), 6.90$ (d, $J=8.0$ $\mathrm{Hz}, 1 \mathrm{H}), 6.50$ (d, $J=7.7 \mathrm{~Hz}, 1 \mathrm{H}) ;{ }^{13} \mathrm{C}$ NMR (125 MHz, DMSO- $\left.d_{6}\right): \delta 163.56,161.32$, $157.80,152.12,139.93,137.36,131.38,130.71,129.39,128.30,125.23,114.73$, 114.59, 113.51, 106.42, 103.47; HRMS: $m / z[\mathrm{M}+\mathrm{H}]^{+}$calcd for $\mathrm{C}_{18} \mathrm{H}_{13} \mathrm{ON}_{3}, 288.1131$; found, 288.1129 .

3-(2-(4-methoxyphenyl)pyrimidin-4-yl)-1H-indol-4-ol (2b). Yield: 52\%; pale yellow solid; m.p. $>210{ }^{\circ} \mathrm{C} ;{ }^{1} \mathrm{H}$ NMR (500 MHz, DMSO- $\left.d_{6}\right): \delta 13.55(\mathrm{~s}, 1 \mathrm{H}), 12.00$ (s, $1 \mathrm{H}), 8.68(\mathrm{~d}, J=5.6 \mathrm{~Hz}, 1 \mathrm{H}), 8.50(\mathrm{~d}, J=2.8 \mathrm{~Hz}, 1 \mathrm{H}), 8.21(\mathrm{~d}, J=8.8 \mathrm{~Hz}, 2 \mathrm{H}), 7.91$ $(\mathrm{d}, J=5.6 \mathrm{~Hz}, 1 \mathrm{H}), 7.15(\mathrm{~d}, J=8.8 \mathrm{~Hz}, 2 \mathrm{H}), 7.05(\mathrm{t}, J=7.9 \mathrm{~Hz}, 1 \mathrm{H}), 6.89$ (d, $J=7.9$ $\mathrm{Hz}, 1 \mathrm{H}), 6.49(\mathrm{~d}, J=7.6 \mathrm{~Hz}, 1 \mathrm{H}), 3.86(\mathrm{~s}, 3 \mathrm{H}) ;{ }^{13} \mathrm{C}$ NMR (125 MHz, DMSO- $\left.d_{6}\right): \delta$ $163.24,162.06,161.15,157.73,152.16,139.88,130.49,129.98,129.64,125.20$, 114.79, 114.77, 113.83, 113.59, 106.32, 103.41, 55.86; HRMS: $m / z[\mathrm{M}+\mathrm{H}]^{+}$calcd for $\mathrm{C}_{19} \mathrm{H}_{15} \mathrm{O}_{2} \mathrm{~N}_{3}, 318.1238$; found, 318.1237.

3-(2-(3-methoxyphenyl)pyrimidin-4-yl)-1H-indol-4-ol (2c). Yield: 38\%; yellow solid; m.p. 207-209 ${ }^{\circ} \mathrm{C}$; ${ }^{1} \mathrm{H}$ NMR (500 MHz, DMSO-d $): \delta 13.39$ (s, 1H), 12.04 (s, $1 \mathrm{H}), 8.73(\mathrm{~d}, J=5.6 \mathrm{~Hz}, 1 \mathrm{H}), 8.53(\mathrm{~d}, J=2.7 \mathrm{~Hz}, 1 \mathrm{H}), 8.00(\mathrm{~d}, J=5.6 \mathrm{~Hz}, 1 \mathrm{H}), 7.81$ $(\mathrm{d}, J=7.8 \mathrm{~Hz}, 1 \mathrm{H}), 7.78(\mathrm{~s}, 1 \mathrm{H}), 7.51(\mathrm{t}, J=7.9 \mathrm{~Hz}, 1 \mathrm{H}), 7.16(\mathrm{~d}, J=8.1 \mathrm{~Hz}, 1 \mathrm{H})$, 7.05 (t, $J=7.8 \mathrm{~Hz}, 1 \mathrm{H}), 6.89$ (d, $J=8.0 \mathrm{~Hz}, 1 \mathrm{H}), 6.49$ (d, $J=7.7 \mathrm{~Hz}, 1 \mathrm{H}), 3.87$ (s, $3 \mathrm{H}) ;{ }^{13} \mathrm{C}$ NMR (125 MHz, DMSO-d6): $\delta 163.34,161.31,160.10,157.75,152.13$, $139.92,138.74,130.73,130.52,125.24,120.57,117.21,114.70,113.50,113.47$, 106.46, 103.47, 55.68; HRMS: $m / z[\mathrm{M}+\mathrm{H}]^{+}$calcd for $\mathrm{C}_{19} \mathrm{H}_{15} \mathrm{O}_{2} \mathrm{~N}_{3}, 318.1237$; found, 318.1231 .

3-(2-(4-fluorophenyl)pyrimidin-4-yl)-1H-indol-4-ol (2d). Yield: 55\%; yellow 
solid; m.p. 189-191 ${ }^{\circ} \mathrm{C}$; ${ }^{1} \mathrm{H}$ NMR (500 MHz, DMSO-d $): \delta 13.39$ (s, 1H), 12.04 (s, 1H), $8.72(\mathrm{~d}, J=5.6 \mathrm{~Hz}, 1 \mathrm{H}), 8.53(\mathrm{~d}, J=2.9 \mathrm{~Hz}, 1 \mathrm{H}), 8.27(\mathrm{dd}, J=8.7,5.6 \mathrm{~Hz}, 2 \mathrm{H})$, $7.99(\mathrm{~d}, J=5.6 \mathrm{~Hz}, 1 \mathrm{H}), 7.44(\mathrm{t}, J=8.8 \mathrm{~Hz}, 2 \mathrm{H}), 7.06(\mathrm{t}, J=7.9 \mathrm{~Hz}, 1 \mathrm{H}), 6.90$ (d, $J=$ $8.0 \mathrm{~Hz}, 1 \mathrm{H}), 6.50(\mathrm{~d}, J=7.6 \mathrm{~Hz}, 1 \mathrm{H}) ;{ }^{13} \mathrm{C} \mathrm{NMR}\left(125 \mathrm{MHz}, \mathrm{DMSO}-d_{6}\right): \delta 165.37$, $163.39,162.59$, 161.34, 157.79, 152.06, 139.92, 133.85, 130.75, 125.26, 116.50, 116.33, 114.72, 114.53, 113.46, 106.42, 103.52; HRMS: $m / z[\mathrm{M}+\mathrm{H}]^{+}$calcd for $\mathrm{C}_{18} \mathrm{H}_{12} \mathrm{ON}_{3} \mathrm{~F}, 306.1037$; found, 306.1030.

3-(2-(3-fluorophenyl)pyrimidin-4-yl)-1H-indol-4-ol (2e). Yield: 40\%; yellow solid; m.p. 159-161 ${ }^{\circ} \mathrm{C}$; ${ }^{1} \mathrm{H}$ NMR (500 MHz, DMSO- $\left.d_{6}\right): \delta 13.30(\mathrm{~s}, 1 \mathrm{H}), 12.07$ (s, $1 \mathrm{H}), 8.75(\mathrm{~d}, J=5.6 \mathrm{~Hz}, 1 \mathrm{H}), 8.55(\mathrm{~d}, J=3.1 \mathrm{~Hz}, 1 \mathrm{H}), 8.09-8.06(\mathrm{~m}, 1 \mathrm{H}), 8.04(\mathrm{~d}, J$ $=5.7 \mathrm{~Hz}, 1 \mathrm{H}), 7.67(\mathrm{t}, J=8.0,1 \mathrm{H}), 7.06(\mathrm{t}, J=7.9,2 \mathrm{H}), 6.89(\mathrm{~d}, J=8.1 \mathrm{~Hz}, 2 \mathrm{H})$, $6.51(\mathrm{~d}, J=7.7 \mathrm{~Hz}, 1 \mathrm{H}) ;{ }^{13} \mathrm{C}$ NMR $\left(125 \mathrm{MHz}, \mathrm{DMSO}-d_{6}\right): \delta 163.91,162.28,161.98$, $161.45,157.79,152.02,139.94,136.91,131.57,130.97,125.29,118.37,118.20$, 115.10, 113.38, 106.83, 106.51, 103.57; HRMS: $m / z[\mathrm{M}+\mathrm{H}]^{+}$calcd for $\mathrm{C}_{18} \mathrm{H}_{12} \mathrm{ON}_{3} \mathrm{~F}$, 306.1037; found, 306.1033.

3-(2-(p-tolyl)pyrimidin-4-yl)-1 $\boldsymbol{H}$-indol-4-ol (2f). Yield: 54\%; yellow solid; m.p. 175-177 ${ }^{\circ} \mathrm{C} ;{ }^{1} \mathrm{H}$ NMR (500 MHz, DMSO- $\left.d_{6}\right): \delta 13.48(\mathrm{~s}, 1 \mathrm{H}), 12.02(\mathrm{~s}, 1 \mathrm{H}), 8.71(\mathrm{~d}, J$ $=3.9 \mathrm{~Hz}, 1 \mathrm{H}), 8.51(\mathrm{~s}, 1 \mathrm{H}), 8.12(\mathrm{~d}, J=6.9 \mathrm{~Hz}, 2 \mathrm{H}), 7.96(\mathrm{~d}, J=4.2 \mathrm{~Hz}, 1 \mathrm{H}), 7.40(\mathrm{~d}$, $J=7.3 \mathrm{~Hz}, 2 \mathrm{H}), 7.05(\mathrm{t}, J=7.1 \mathrm{~Hz}, 1 \mathrm{H}), 6.89$ (d, $J=7.2 \mathrm{~Hz}, 1 \mathrm{H}), 6.49$ (d, $J=6.9 \mathrm{~Hz}$, 1H), $2.40(\mathrm{~s}, 3 \mathrm{H}) ;{ }^{13} \mathrm{C}$ NMR (125 MHz, DMSO- $\left.d_{6}\right): \delta 163.57,161.23,157.77,152.15$, $141.32,139.90,134.63,130.57,129.99,128.27,125.21,114.74,114.30,113.56$, 106.39, 103.42, 21.44; HRMS: $m / z[\mathrm{M}+\mathrm{H}]^{+}$calcd for $\mathrm{C}_{19} \mathrm{H}_{15} \mathrm{ON}_{3}, 302.1288$; found, 302.1281 .

3-(2-(m-tolyl)pyrimidin-4-yl)-1H-indol-4-ol (2g). Yield: 66\%; yellow solid; m.p. 144-146 ${ }^{\circ} \mathrm{C} ;{ }^{1} \mathrm{H}$ NMR (500 MHz, DMSO- $\left.d_{6}\right): \delta 13.41(\mathrm{~s}, 1 \mathrm{H}), 12.02(\mathrm{~s}, 1 \mathrm{H}), 8.72(\mathrm{~d}, J$ $=5.6 \mathrm{~Hz}, 1 \mathrm{H}), 8.52(\mathrm{~d}, J=3.0 \mathrm{~Hz}, 1 \mathrm{H}), 8.06(\mathrm{~s}, 1 \mathrm{H}), 7.99(\mathrm{t}, J=6.8 \mathrm{~Hz}, 2 \mathrm{H}), 7.48(\mathrm{t}$, $J=7.6 \mathrm{~Hz}, 1 \mathrm{H}), 7.40(\mathrm{~d}, J=7.5 \mathrm{~Hz}, 1 \mathrm{H}), 7.05(\mathrm{dd}, J=9.5,6.2 \mathrm{~Hz}, 1 \mathrm{H}), 6.89$ (d, $J=$ $8.0 \mathrm{~Hz}, 1 \mathrm{H}), 6.49(\mathrm{~d}, J=7.7 \mathrm{~Hz}, 1 \mathrm{H}), 2.43(\mathrm{~s}, 3 \mathrm{H}) ;{ }^{13} \mathrm{C} \mathrm{NMR}\left(125 \mathrm{MHz}, \mathrm{DMSO}-d_{6}\right)$ : $\delta 163.67,161.29,157.75,152.15,139.92,138.55,137.34,131.99,130.64,129.29$, 
129.03, 125.37, 125.22, 114.72, 114.52, 113.54, 106.44, 103.43, 21.61 ; HRMS: $m / z$ $[\mathrm{M}+\mathrm{H}]^{+}$calcd for $\mathrm{C}_{19} \mathrm{H}_{15} \mathrm{ON}_{3}, 302.1288$; found, 302.1281 .

4.1.3. General procedure for synthesis of 5a $\sim \mathbf{g}$ meridianin analogs.

To the solution of $\mathbf{1 a} \sim \mathbf{g}$ in DMF ( $5 \mathrm{~mL}$ ) was added 1,6-dibromohexane (5.0 equiv.) respectively, and the mixture was stirred at $50^{\circ} \mathrm{C}$ for $5 \mathrm{~h}$. Then, the reaction mixture was removed under vacuum and the residue was poured into ice water and extracted with ethyl acetate $(3 \times 50 \mathrm{~mL})$. The combined organic layers were washed with brine, dried over magnesium sulfate anhydrous and concentrated to give intermediates 23 29, and used in the next step without further purification. To a stirring solution of compounds 23 29 in ethanol was added thiocarbamide (2.0 equiv.) and the mixture was stirred at $65^{\circ} \mathrm{C}$ for $3 \mathrm{~h}$. Then, the solvent was removed under vacuum and the residue was purified by silica gel column chromatography (dichloromethane/methanol 10:1) to give get the final target compounds 5a-g.

2-(6-(3-(2-phenylpyrimidin-4-yl)-1H-indol-1-yl)hexyl)isothiouronium

(5a). Yield: 70\%; yellow oily substance; ${ }^{1} \mathrm{H}$ NMR (500 MHz, DMSO-d $)$ ): $\delta 8.97$ (s, $J=$ $28.0 \mathrm{~Hz}, 3 \mathrm{H}), 8.73(\mathrm{~d}, J=5.4 \mathrm{~Hz}, 1 \mathrm{H}), 8.68-8.64(\mathrm{~m}, 1 \mathrm{H}), 8.56(\mathrm{~s}, 1 \mathrm{H}), 8.53-8.49$ (m, 2H), $7.77(\mathrm{~d}, J=5.4 \mathrm{~Hz}, 1 \mathrm{H}), 7.64-7.52(\mathrm{~m}, 4 \mathrm{H}), 7.32-7.26(\mathrm{~m}, 2 \mathrm{H}), 4.29$ (t, $J=7.1$ $\mathrm{Hz}, 2 \mathrm{H}), 3.11(\mathrm{t}, J=7.3 \mathrm{~Hz}, 2 \mathrm{H}), 1.89-1.79(\mathrm{~m}, 2 \mathrm{H}), 1.57(\mathrm{dt}, J=14.9,7.5 \mathrm{~Hz}, 2 \mathrm{H})$, $1.46-1.36(\mathrm{~m}, 2 \mathrm{H}), 1.31(\mathrm{dt}, J=14.8,7.3 \mathrm{~Hz}, 2 \mathrm{H}) ;{ }^{13} \mathrm{C} \mathrm{NMR}\left(125 \mathrm{MHz}, \mathrm{DMSO}-d_{6}\right)$ : $\delta 170.30,163.66,162.26,157.11,138.51,137.55,133.02,131.02,129.13,128.10$, $126.13,122.87,122.35,121.73,114.51,112.85,111.20,46.44,30.49,29.84,28.71$, 27.86, 26.06; HRMS calcd for $\mathrm{C}_{25} \mathrm{H}_{27} \mathrm{~N}_{5} \mathrm{~S}[\mathrm{M}+\mathrm{H}]^{+} 430.2060$, found: 430.2065 。

\section{2-(6-(3-(2-(4-methoxyphenyl)pyrimidin-4-yl)-1 H-indol-1-yl)hexyl)isothiouron}

ium (5b). Yield: 78\%; pale yellow solid; m.p. 191-193 ${ }^{\circ} \mathrm{C}$; ${ }^{1} \mathrm{H}$ NMR (500 MHz, DMSO-d $\left.)_{6}\right) \delta 8.96(\mathrm{~s}, 3 \mathrm{H}), 8.70(\mathrm{~d}, J=5.3 \mathrm{~Hz}, 1 \mathrm{H}), 8.64(\mathrm{dd}, J=6.2,2.7 \mathrm{~Hz}, 1 \mathrm{H})$, $8.53(\mathrm{~s}, 1 \mathrm{H}), 8.41(\mathrm{~d}, J=8.0 \mathrm{~Hz}, 2 \mathrm{H}), 7.73$ (d, $J=5.4 \mathrm{~Hz}, 1 \mathrm{H}), 7.64-7.59$ (m, 1H), $7.38(\mathrm{~d}, J=7.6 \mathrm{~Hz}, 2 \mathrm{H}), 7.33-7.25(\mathrm{~m}, 2 \mathrm{H}), 4.29$ (t, $J=6.6 \mathrm{~Hz}, 2 \mathrm{H}), 3.10$ (t, $J=7.3$ $\mathrm{Hz}, 2 \mathrm{H}), 2.40$ (s, 3H), 1.88-1.80 (m, 2H), 1.56 (dd, $J=14.1,6.9 \mathrm{~Hz}, 2 \mathrm{H}), 1.39$ (dd, $J$ 
$=14.0,6.8 \mathrm{~Hz}, 2 \mathrm{H}), 1.35-1.26(\mathrm{~m}, 2 \mathrm{H}) ;{ }^{13} \mathrm{C}$ NMR (125 MHz, DMSO- $\left.d_{6}\right): \delta 170.27$, $163.72,162.17,157.06,140.73,137.54,135.86,132.91,129.74,128.08,126.13$, $122.83,122.34,121.69,114.23,112.90,111.18,46.43,30.48,29.85,28.71,27.86$, 26.06, 21.51; HRMS calcd for $\mathrm{C}_{26} \mathrm{H}_{29} \mathrm{ON}_{5} \mathrm{~S}[\mathrm{M}+\mathrm{H}]^{+} 460.2166$, found: 460.2165 。

\section{2-(6-(3-(2-(3-methoxyphenyl)pyrimidin-4-yl)-1 H-indol-1-yl)hexyl)isothiouron}

ium (5c). Yield: 82\%; pale yellow solid; m.p. 155-157 ${ }^{\circ} \mathrm{C}$; ${ }^{1} \mathrm{H}$ NMR (500 MHz, DMSO-d $\left.)_{6}\right): \delta .99(\mathrm{~s}, 3 \mathrm{H}), 8.73(\mathrm{~d}, J=5.4 \mathrm{~Hz}, 1 \mathrm{H}), 8.66(\mathrm{dd}, J=5.7,3.2 \mathrm{~Hz}, 1 \mathrm{H})$, $8.55(\mathrm{~s}, 1 \mathrm{H}), 8.11(\mathrm{~d}, J=7.7 \mathrm{~Hz}, 1 \mathrm{H}), 8.07(\mathrm{~s}, 1 \mathrm{H}), 7.77$ (d, $J=5.4 \mathrm{~Hz}, 1 \mathrm{H})$, $7.64-7.60(\mathrm{~m}, 1 \mathrm{H}), 7.50(\mathrm{t}, J=7.9 \mathrm{~Hz}, 1 \mathrm{H}), 7.29(\mathrm{dd}, J=6.1,3.1 \mathrm{~Hz}, 2 \mathrm{H}), 7.13(\mathrm{dd}, J$ $=8.1,1.9 \mathrm{~Hz}, 1 \mathrm{H}), 4.29(\mathrm{t}, J=6.9 \mathrm{~Hz}, 2 \mathrm{H}), 3.89(\mathrm{~s}, 3 \mathrm{H}), 3.11(\mathrm{t}, J=7.3 \mathrm{~Hz}, 2 \mathrm{H})$, $1.90-1.80(\mathrm{~m}, 2 \mathrm{H}), 1.61-1.51(\mathrm{~m}, 2 \mathrm{H}), 1.40(\mathrm{dt}, J=14.5,7.3 \mathrm{~Hz}, 2 \mathrm{H}), 1.31(\mathrm{dt}, J=$ 14.5, 7.5 Hz, 2H); ${ }^{13} \mathrm{C}$ NMR (125 MHz, DMSO- $\left.d_{6}\right): \delta 170.31,163.40,162.23,160.00$, $157.06,139.99,137.55,133.02,130.25,126.14,122.88,122.31,121.68,120.46$, $116.88,114.59,113.05,112.80,111.23,55.58,46.44,30.48,29.84,28.71,27.86$, 26.06; HRMS calcd for $\mathrm{C}_{26} \mathrm{H}_{29} \mathrm{ON}_{5} \mathrm{~S}[\mathrm{M}+\mathrm{H}]^{+} 460.2166$, found: 460.2166 。

2-(6-(3-(2-(4-fluorophenyl)pyrimidin-4-yl)-1H-indol-1-yl)hexyl)isothiouroniu m (5d). Yield: 58\%; yellow oily substance; ${ }^{1} \mathrm{H}$ NMR (500 MHz, DMSO- $\left.d_{6}\right): \delta 8.99$ (s, $3 \mathrm{H}), 8.71(\mathrm{~d}, J=5.4 \mathrm{~Hz}, 1 \mathrm{H}), 8.62(\mathrm{dd}, J=6.0,3.0 \mathrm{~Hz}, 1 \mathrm{H}), 8.58-8.53(\mathrm{~m}, 3 \mathrm{H}), 7.77$ (d, $J=5.5 \mathrm{~Hz}, 1 \mathrm{H}), 7.62(\mathrm{dd}, J=6.0,3.1 \mathrm{~Hz}, 1 \mathrm{H}), 7.40(\mathrm{t}, J=8.8 \mathrm{~Hz}, 2 \mathrm{H}), 7.33-7.26$ (m, 2H), $4.28(\mathrm{t}, J=7.0 \mathrm{~Hz}, 2 \mathrm{H}), 3.11(\mathrm{t}, J=7.3 \mathrm{~Hz}, 2 \mathrm{H}), 1.84(\mathrm{dt}, J=14.5,7.2 \mathrm{~Hz}$, 2H), 1.57 (dt, $J=14.7,7.5 \mathrm{~Hz}, 2 \mathrm{H}), 1.40$ (dt, $J=14.5,7.3 \mathrm{~Hz}, 2 \mathrm{H}), 1.31$ (dt, $J=15.1$, $7.6 \mathrm{~Hz}, 2 \mathrm{H}) ;{ }^{13} \mathrm{C}$ NMR (125 MHz, DMSO-d $): \delta 170.32,165.26,163.29,162.76$, 162.30, 157.12, 137.55, 134.99, 133.13, 130.42 (d, $J=8.7 \mathrm{~Hz}), 126.08,122.88,122.28$, $121.75,116.14,115.97,114.43,112.77,111.22,46.45,30.48,29.83,28.72,27.85$, 26.05; HRMS calcd for $\mathrm{C}_{25} \mathrm{H}_{26} \mathrm{~N}_{5} \mathrm{FS}[\mathrm{M}+\mathrm{H}]^{+} 448.1966$, found: 448.1968 。

\section{2-(6-(3-(2-(3-fluorophenyl)pyrimidin-4-yl)-1H-indol-1-yl)hexyl)isothiouroniu} m (5e). Yield: 77\%; yellow oily substance; ${ }^{1} \mathrm{H}$ NMR (500 MHz, DMSO- $\left.d_{6}\right): \delta 9.00$ (s, $3 \mathrm{H}), 8.75(\mathrm{~d}, J=5.5 \mathrm{~Hz}, 1 \mathrm{H}), 8.62-8.57(\mathrm{~m}, 2 \mathrm{H}), 8.36(\mathrm{~d}, J=7.8 \mathrm{~Hz}, 1 \mathrm{H}), 8.19(\mathrm{dd}, J$ $=6.4,5.4 \mathrm{~Hz}, 1 \mathrm{H}), 7.81(\mathrm{~d}, J=5.5 \mathrm{~Hz}, 1 \mathrm{H}), 7.67-7.61(\mathrm{~m}, 2 \mathrm{H}), 7.40(\mathrm{td}, J=8.4,2.0$ $\mathrm{Hz}, 1 \mathrm{H}), 7.33-7.26(\mathrm{~m}, 2 \mathrm{H}), 4.29(\mathrm{t}, J=7.0 \mathrm{~Hz}, 2 \mathrm{H}), 3.11(\mathrm{t}, J=7.3 \mathrm{~Hz}, 2 \mathrm{H})$, 
1.88-1.80 (m, 2H), 1.57 (dt, $J=14.8,7.5 \mathrm{~Hz}, 2 \mathrm{H}), 1.40(\mathrm{dt}, J=14.5,7.3 \mathrm{~Hz}, 2 \mathrm{H})$, $1.31(\mathrm{dt}, J=14.9,7.5 \mathrm{~Hz}, 2 \mathrm{H}) ;{ }^{13} \mathrm{C} \mathrm{NMR}\left(125 \mathrm{MHz}, \mathrm{DMSO}-d_{6}\right): \delta 170.33,163.97$, $162.40(\mathrm{~d}, J=13.0 \mathrm{~Hz}), 162.04,157.21,141.11(\mathrm{~d}, J=7.6 \mathrm{~Hz}), 137.58,133.28$, $131.26(\mathrm{~d}, J=8.1 \mathrm{~Hz}), 126.05,124.14,122.91,122.15,121.80,117.92,117.76$, $114.99,114.53,114.35,112.66,111.27,46.47,30.47,29.84,28.72,27.85,26.06$;

HRMS calcd for $\mathrm{C}_{25} \mathrm{H}_{26} \mathrm{~N}_{5} \mathrm{FS}[\mathrm{M}+\mathrm{H}]^{+} 448.1966$, found: 448.1974。

\section{2-(6-(3-(2-(p-tolyl)pyrimidin-4-yl)-1H-indol-1-yl)hexyl)isothiouronium (5f).}

Yield: 60\%; white solid; m.p. 205-207 ${ }^{\circ} \mathrm{C}$; ${ }^{1} \mathrm{H}$ NMR (500 MHz, DMSO- $d_{6}$ ): $\delta 8.96$ (s, $3 \mathrm{H}), 8.70(\mathrm{~d}, J=5.3 \mathrm{~Hz}, 1 \mathrm{H}), 8.64(\mathrm{dd}, J=6.2,2.7 \mathrm{~Hz}, 1 \mathrm{H}), 8.53(\mathrm{~s}, 1 \mathrm{H}), 8.41(\mathrm{~d}, J=$ $8.0 \mathrm{~Hz}, 2 \mathrm{H}), 7.73(\mathrm{~d}, J=5.4 \mathrm{~Hz}, 1 \mathrm{H}), 7.64-7.59(\mathrm{~m}, 1 \mathrm{H}), 7.38(\mathrm{~d}, J=7.6 \mathrm{~Hz}, 2 \mathrm{H})$, $7.33-7.25(\mathrm{~m}, 2 \mathrm{H}), 4.29(\mathrm{t}, J=6.6 \mathrm{~Hz}, 2 \mathrm{H}), 3.10(\mathrm{t}, J=7.3 \mathrm{~Hz}, 2 \mathrm{H}), 2.40(\mathrm{~s}, 3 \mathrm{H})$, 1.88-1.80 (m, 2H), $1.56(\mathrm{dd}, J=14.1,6.9 \mathrm{~Hz}, 2 \mathrm{H}), 1.39(\mathrm{dd}, J=14.0,6.8 \mathrm{~Hz}, 2 \mathrm{H})$, $1.35-1.26(\mathrm{~m}, 2 \mathrm{H}) ;{ }^{13} \mathrm{C}$ NMR (125 MHz, DMSO-d $): \delta 170.27,163.72,162.17$, $157.06,140.73,137.54,135.86,132.91,129.74,128.08,126.13,122.83,122.34$, $121.69,114.23,112.90,111.18,46.43,30.48,29.85,28.71,27.86,26.06,21.51$;

HRMS calcd for $\mathrm{C}_{26} \mathrm{H}_{29} \mathrm{~N}_{5} \mathrm{~S}[\mathrm{M}+\mathrm{H}]^{+} 444.2216$, found: 444.2228 。

2-(6-(3-(2-(m-tolyl)pyrimidin-4-yl)-1H-indol-1-yl)hexyl)isothiouronium (5g).

Yield: 74\%; yellow solid; m.p. $125-127{ }^{\circ} \mathrm{C} ;{ }^{1} \mathrm{H}$ NMR (500 MHz, DMSO- $d_{6}$ ): $\delta 8.96$ (s, $3 \mathrm{H}), 8.72(\mathrm{~d}, J=5.4 \mathrm{~Hz}, 1 \mathrm{H}), 8.68-8.63(\mathrm{~m}, 1 \mathrm{H}), 8.54(\mathrm{~s}, 1 \mathrm{H}), 8.32(\mathrm{~d}, J=7.2 \mathrm{~Hz}$, 2H), $7.76(\mathrm{~d}, J=5.4 \mathrm{~Hz}, 1 \mathrm{H}), 7.65-7.59(\mathrm{~m}, 1 \mathrm{H}), 7.47$ (t, $J=7.7 \mathrm{~Hz}, 1 \mathrm{H}), 7.36$ (d, $J=$ $7.4 \mathrm{~Hz}, 1 \mathrm{H}), 7.32-7.26(\mathrm{~m}, 2 \mathrm{H}), 4.29$ (t, $J=6.9 \mathrm{~Hz}, 2 \mathrm{H}), 3.11$ (t, $J=7.3 \mathrm{~Hz}, 2 \mathrm{H}), 2.45$ (s, 3H), 1.89-1.80 (m, 2H), 1.59-1.53 (m, 2H), $1.40(\mathrm{dt}, J=14.7,7.3 \mathrm{~Hz}, 2 \mathrm{H})$, 1.35-1.28 (m, 2H); ${ }^{13} \mathrm{C}$ NMR (125 MHz, DMSO- $\left.d_{6}\right): \delta$ 170.30, 163.74, 162.19, 157.07, 138.48, 138.16, 137.54, 132.95, 131.64, 129.04, 128.72, 126.13, 125.31, $122.84,122.31,121.70,114.45,112.88,111.20,46.44,30.49,29.85,28.71,27.86$, 26.06, 21.71; HRMS calcd for $\mathrm{C}_{26} \mathrm{H}_{29} \mathrm{~N}_{5} \mathrm{~S}[\mathrm{M}+\mathrm{H}]^{+} 444.2216$, found: 444.2219。

\subsubsection{General procedure for synthesis of $\mathbf{6 a} \sim \mathbf{g}$ meridianin analogs.}

To the solution of $\mathbf{4 a} \sim \mathbf{g}$ in DMF (5 mL) was added 1,6-dibromohexane (5.0 equiv.) respectively, and the mixture was stirred at $50^{\circ} \mathrm{C}$ for $5 \mathrm{~h}$. Then, the reaction mixture 
was removed under vacuum and the residue was poured into ice water and extracted with ethyl acetate $(3 \times 50 \mathrm{~mL})$. The combined organic layers were washed with brine, dried over magnesium sulfate anhydrous and concentrated to give intermediates 30 36, and used in the next step without further purification. To a stirring solution of compounds 30 36 in ethanol was added thiocarbamide (2.0 equiv.), and the mixture was stirred at $65^{\circ} \mathrm{C}$ for $3 \mathrm{~h}$. Then, the solvent was removed under vacuum and the residue was purified by silica gel column chromatography (dichloromethane/methanol 10:1) to give get the final target compounds $\mathbf{6 a - g}$.

2-(6-(6-bromo-3-(2-phenylpyrimidin-4-yl)-1H-indol-1-yl)hexyl)isothiouroniu m (6a). Yield: 84\%; white solid; m.p. 131-133 ${ }^{\circ} \mathrm{C}$; ${ }^{1} \mathrm{H}$ NMR (500 MHz, DMSO- $\left.d_{6}\right): \delta$ $9.20(\mathrm{~s}, 3 \mathrm{H}), 8.75(\mathrm{~d}, J=5.4 \mathrm{~Hz}, 1 \mathrm{H}), 8.62-8.55(\mathrm{~m}, 2 \mathrm{H}), 8.52-8.47(\mathrm{~m}, 2 \mathrm{H}), 7.92$ $(\mathrm{d}, J=1.0 \mathrm{~Hz}, 1 \mathrm{H}), 7.78(\mathrm{~d}, J=5.4 \mathrm{~Hz}, 1 \mathrm{H}), 7.56(\mathrm{p}, J=6.0 \mathrm{~Hz}, 3 \mathrm{H}), 7.43(\mathrm{dd}, J=$ 8.5, 1.4 Hz, 1H), 4.27 (t, $J=7.0 \mathrm{~Hz}, 2 \mathrm{H}), 3.06$ (t, $J=7.2 \mathrm{~Hz}, 2 \mathrm{H}), 1.82$ (dt, $J=14.5$, $7.2 \mathrm{~Hz}, 2 \mathrm{H}), 1.57$ (dt, $J=14.7,7.3 \mathrm{~Hz}, 2 \mathrm{H}), 1.45$ - 1.36 (m, 2H), 1.35 - 1.27 (m, $2 \mathrm{H}) ;{ }^{13} \mathrm{C}$ NMR (125 MHz, DMSO- $\left.d_{6}\right): \delta 169.33,163.72,161.83,157.31,138.45$, $138.37,133.72,131.08,129.16,128.13,125.07,124.63,124.02,115.83,114.62$, 114.05, 113.10, 46.55, 30.35, 29.86, 28.85, 27.88, 26.02; HRMS: $m / z[\mathrm{M}+\mathrm{H}]^{+}$calcd for $\mathrm{C}_{25} \mathrm{H}_{26} \mathrm{~N}_{5} \mathrm{BrS}$, 510.1145; found, 510.1130.

2-(6-(6-bromo-3-(2-(4-methoxyphenyl)pyrimidin-4-yl)-1H-indol-1-yl)hexyl)is othiouronium (6b). Yield: 68\%; pale yellow solid; m.p. 54-56 ${ }^{\circ} \mathrm{C}$; ${ }^{1} \mathrm{H}$ NMR (500 MHz, DMSO- $\left.d_{6}\right): \delta 9.32(\mathrm{~s}, 3 \mathrm{H}), 8.74(\mathrm{~d}, J=4.6 \mathrm{~Hz}, 1 \mathrm{H}), 8.57$ (dd, $J=26.4,14.5 \mathrm{~Hz}$, 2H), $8.13-7.99(\mathrm{~m}, 2 \mathrm{H}), 7.92(\mathrm{~s}, 1 \mathrm{H}), 7.78(\mathrm{~d}, J=4.3 \mathrm{~Hz}, 1 \mathrm{H}), 7.53-7.38(\mathrm{~m}, 2 \mathrm{H})$, $7.12(\mathrm{~d}, J=7.4 \mathrm{~Hz}, 1 \mathrm{H}), 4.27(\mathrm{t}, 2 \mathrm{H}), 3.88(\mathrm{~s}, 3 \mathrm{H}), 3.03(\mathrm{t}, 2 \mathrm{H}), 1.81$ (dt, 2H), 1.56 (dt, 2H), $1.40(\mathrm{~m}, 2 \mathrm{H}), 1.30(\mathrm{~m}, 2 \mathrm{H}) ;{ }^{13} \mathrm{C} \mathrm{NMR}\left(125 \mathrm{MHz}, \mathrm{DMSO}-d_{6}\right): \delta 168.64,163.46$, $161.80,160.00,157.26,139.86,138.44,133.73,130.26,125.09,124.56,123.94$, 120.49, 117.08, 115.84, 114.73, 114.08, 113.05, 112.89, 55.58, 46.54, 30.25, 29.86, 28.94, 27.87, 26.02; HRMS: $m / z[\mathrm{M}+\mathrm{H}]^{+}$calcd for $\mathrm{C}_{26} \mathrm{H}_{28} \mathrm{~N}_{5}{ }^{81} \mathrm{BrS}, 540.1250$; found, 540.1236 .

2-(6-(6-bromo-3-(2-(3-methoxyphenyl)pyrimidin-4-yl)-1H-indol-1-yl)hexyl)is 
othiouronium (6c). Yield: 65\%; yellow solid; m.p. 120-122 ${ }^{\circ} \mathrm{C}$; ${ }^{1} \mathrm{H}$ NMR $(500 \mathrm{MHz}$, DMSO- $\left.d_{6}\right): \delta 9.32(\mathrm{~s}, 3 \mathrm{H}), 8.68(\mathrm{~d}, J=5.3 \mathrm{~Hz}, 1 \mathrm{H}), 8.58(\mathrm{~d}, J=8.6 \mathrm{~Hz}, 1 \mathrm{H}), 8.54(\mathrm{~s}$, $1 \mathrm{H}), 8.44(\mathrm{~d}, J=8.8 \mathrm{~Hz}, 2 \mathrm{H}), 7.91(\mathrm{~s}, 1 \mathrm{H}), 7.69(\mathrm{~d}, J=5.3 \mathrm{~Hz}, 1 \mathrm{H}), 7.41(\mathrm{dd}, J=8.5$, $1.4 \mathrm{~Hz}, 1 \mathrm{H}), 7.11(\mathrm{~d}, J=8.9 \mathrm{~Hz}, 2 \mathrm{H}), 4.26(\mathrm{t}, J=6.9 \mathrm{~Hz}, 2 \mathrm{H}), 3.85(\mathrm{~s}, 3 \mathrm{H}), 3.03$ (t, $J$ $=7.1 \mathrm{~Hz}, 2 \mathrm{H}), 1.80(\mathrm{dd}, J=14.4,7.2 \mathrm{~Hz}, 2 \mathrm{H}), 1.61-1.53(\mathrm{~m}, 2 \mathrm{H}), 1.39(\mathrm{dd}, J=14.3$, $7.2 \mathrm{~Hz}, 2 \mathrm{H}), 1.31$ (d, $J=6.6 \mathrm{~Hz}, 2 \mathrm{H}) ;{ }^{13} \mathrm{C}$ NMR (125 MHz, DMSO-d $): \delta 168.51$, $163.55,161.81,161.68,157.18,138.42,133.58,130.89,129.76,125.08,124.52$, 124.03, 115.78, 114.49, 114.01, 113.89, 113.20, 55.77, 46.52, 30.24, 29.87, 28.95, 27.88, 26.03; HRMS: $m / z[\mathrm{M}+\mathrm{H}]^{+}$calcd for $\mathrm{C}_{26} \mathrm{H}_{28} \mathrm{~N}_{5}{ }^{81} \mathrm{BrS}, 540.1250$; found, 540.1234 .

\section{2-(6-(6-bromo-3-(2-(4-fluorophenyl)pyrimidin-4-yl)-1H-indol-1-yl)hexyl)isot}

hiouronium (6d). Yield: 68\%; yellow oily substance; ${ }^{1} \mathrm{H}$ NMR (500 MHz, DMSO- $\left.d_{6}\right)$ : $\delta 9.33$ (s, 3H), 8.73 (d, $J=5.4 \mathrm{~Hz}, 1 \mathrm{H}), 8.60-8.48(\mathrm{~m}, 4 \mathrm{H}), 7.92(\mathrm{~d}, J=1.2 \mathrm{~Hz}, 1 \mathrm{H})$, $7.77(\mathrm{~d}, J=5.4 \mathrm{~Hz}, 1 \mathrm{H}), 7.44-7.34(\mathrm{~m}, 3 \mathrm{H}), 4.26(\mathrm{t}, J=7.0 \mathrm{~Hz}, 2 \mathrm{H}), 3.03(\mathrm{t}, J=7.1$ $\mathrm{Hz}, 2 \mathrm{H}), 1.80$ (dd, $J=14.3,7.2 \mathrm{~Hz}, 2 \mathrm{H}), 1.56$ (dd, $J=14.1,7.2 \mathrm{~Hz}, 2 \mathrm{H}), 1.44-1.37$ $(\mathrm{m}, 2 \mathrm{H}), 1.34-1.26(\mathrm{~m}, 2 \mathrm{H}) ;{ }^{13} \mathrm{C}$ NMR $\left(125 \mathrm{MHz}, \mathrm{DMSO}-d_{6}\right): \delta 168.61,165.28$, $163.30,162.80,161.86,157.31,138.44,134.87,133.83,130.50,130.43,125.02$, 124.62, 123.97, 116.15, 115.90 (d, $J=19.0 \mathrm{~Hz}), 114.56,114.05,113.02,46.55,30.24$, 29.85, 28.95, 27.86, 26.02 ; HRMS: $m / z[\mathrm{M}+\mathrm{H}]^{+}$calcd for $\mathrm{C}_{25} \mathrm{H}_{25} \mathrm{~N}_{5}{ }^{81} \mathrm{BrFS}$, 528.1050; found, 528.1035 .

\section{2-(6-(6-bromo-3-(2-(3-fluorophenyl)pyrimidin-4-yl)-1H-indol-1-yl)hexyl)isot}

hiouronium (6e). Yield: 75\%; brown solid; m.p. 124-126 ${ }^{\circ} \mathrm{C}$; ${ }^{1} \mathrm{H}$ NMR $(500 \mathrm{MHz}$, DMSO-d $\left.d_{6}\right): \delta 9.31(\mathrm{~s}, 3 \mathrm{H}), 8.76(\mathrm{~d}, J=5.4 \mathrm{~Hz}, 1 \mathrm{H}), 8.59(\mathrm{~s}, 1 \mathrm{H}), 8.53(\mathrm{~d}, J=8.5 \mathrm{~Hz}$, 1H), $8.34(\mathrm{~d}, J=7.8 \mathrm{~Hz}, 1 \mathrm{H}), 8.17(\mathrm{~d}, J=10.4 \mathrm{~Hz}, 1 \mathrm{H}), 7.92$ (d, $J=1.3 \mathrm{~Hz}, 1 \mathrm{H}), 7.81$ $(\mathrm{d}, J=5.4 \mathrm{~Hz}, 1 \mathrm{H}), 7.63(\mathrm{dd}, J=14.0,7.9 \mathrm{~Hz}, 1 \mathrm{H}), 7.45-7.35(\mathrm{~m}, 2 \mathrm{H}), 4.27$ (t, $J=$ $7.1 \mathrm{~Hz}, 2 \mathrm{H}), 3.05$ (t, $J=7.2 \mathrm{~Hz}, 2 \mathrm{H}), 1.81(\mathrm{dd}, J=14.5,7.3 \mathrm{~Hz}, 2 \mathrm{H}), 1.57(\mathrm{dt}, J=$ 14.5, 7.4 Hz, 2H), 1.40 (dt, $J=14.5,7.3 \mathrm{~Hz}, 2 \mathrm{H}), 1.35-1.27(\mathrm{~m}, 2 \mathrm{H}) ;{ }^{13} \mathrm{C}$ NMR $(125$ MHz, DMSO-d $): \delta 168.99,163.96,162.50(\mathrm{~d}, J=3.0 \mathrm{~Hz}), 161.97(\mathrm{~d}, J=13.8 \mathrm{~Hz})$, 157.38, 140.97 (d, $J=7.7 \mathrm{~Hz}), 138.46,133.96,131.26$ (d, $J=8.1 \mathrm{~Hz}), 124.99,124.69$, 124.16, 123.83, 117.98, 117.81, 115.86, 115.12, 114.56, 114.38, 114.10, 112.92, 46.56, 
$30.29,29.85,28.90,27.87,26.02$; HRMS calcd for $\mathrm{C}_{25} \mathrm{H}_{25} \mathrm{~N}_{5} \mathrm{BrFS}[\mathrm{M}+\mathrm{H}]^{+}$ 528.1050, found: 528.1056 。

\section{2-(6-(6-bromo-3-(2-(p-tolyl)pyrimidin-4-yl)-1H-indol-1-yl)hexyl)isothiouroni} um (6f). Yield: 69\%; yellow solid; m.p. 130-131 ${ }^{\circ} \mathrm{C}$; ${ }^{1} \mathrm{H}$ NMR (500 MHz, DMSO-d6): $\delta 9.33(\mathrm{~s}, 3 \mathrm{H}), 8.71(\mathrm{~d}, J=5.3 \mathrm{~Hz}, 1 \mathrm{H}), 8.61-8.53(\mathrm{~m}, 2 \mathrm{H}), 8.38(\mathrm{~d}, J=8.1 \mathrm{~Hz}, 2 \mathrm{H})$, $7.91(\mathrm{~s}, 1 \mathrm{H}), 7.74(\mathrm{~d}, J=5.3 \mathrm{~Hz}, 1 \mathrm{H}), 7.39(\mathrm{dd}, J=25.4,8.2 \mathrm{~Hz}, 3 \mathrm{H}), 4.26$ (t, $J=6.8$ $\mathrm{Hz}, 2 \mathrm{H}), 3.04$ (t, $J=7.1 \mathrm{~Hz}, 2 \mathrm{H}), 2.40$ (s, 3H), $1.86-1.75$ (m, 2H), 1.55 (dd, $J=14.1$, $7.1 \mathrm{~Hz}, 2 \mathrm{H}), 1.39(\mathrm{dd}, J=14.2,7.2 \mathrm{~Hz}, 2 \mathrm{H}), 1.31(\mathrm{~d}, J=6.7 \mathrm{~Hz}, 2 \mathrm{H}) ;{ }^{13} \mathrm{C} \mathrm{NMR}(125$ MHz, DMSO- $\left.d_{6}\right): \delta 168.93,163.77,161.74,157.24,140.80,138.42,135.73,133.63$, 129.76, 128.11, 125.08, 124.56, 124.02, 115.80, 114.36, 114.02, 113.15, 46.53, 30.26, 29.86, 28.91, 27.87, 26.02, 21.50; HRMS calcd for $\mathrm{C}_{26} \mathrm{H}_{29} \mathrm{~N}_{5}{ }^{81} \mathrm{BrS}[\mathrm{M}+\mathrm{H}]^{+}$ 524.1301, found: 524.1306 。

\section{2-(6-(6-bromo-3-(2-(m-tolyl)pyrimidin-4-yl)-1H-indol-1-yl)hexyl)isothiouroni} um (6g). Yield: 80\%; brown solid; m.p. $125-127{ }^{\circ} \mathrm{C}$; ${ }^{1} \mathrm{H}$ NMR (500 MHz, DMSO- $\left.d_{6}\right)$ : $\delta 9.19(\mathrm{~s}, 3 \mathrm{H}), 8.73(\mathrm{~d}, J=5.4 \mathrm{~Hz}, 1 \mathrm{H}), 8.61-8.53(\mathrm{~m}, 2 \mathrm{H}), 8.29(\mathrm{~d}, J=7.6 \mathrm{~Hz}, 2 \mathrm{H})$, $7.92(\mathrm{~d}, J=1.3 \mathrm{~Hz}, 1 \mathrm{H}), 7.76(\mathrm{~d}, J=5.4 \mathrm{~Hz}, 1 \mathrm{H}), 7.49-7.41(\mathrm{~m}, 2 \mathrm{H}), 7.36(\mathrm{~d}, J=$ $7.6 \mathrm{~Hz}, 1 \mathrm{H}), 4.27$ (t, $J=7.1 \mathrm{~Hz}, 2 \mathrm{H}), 3.08$ (t, $J=7.3 \mathrm{~Hz}, 2 \mathrm{H}), 2.44$ (s, 3H), 1.82 (dt, $J$ $=14.6,7.3 \mathrm{~Hz}, 2 \mathrm{H}), 1.57(\mathrm{dt}, J=14.7,7.4 \mathrm{~Hz}, 2 \mathrm{H}), 1.40(\mathrm{dt}, J=14.6,7.3 \mathrm{~Hz}, 2 \mathrm{H})$, $1.30(\mathrm{dt}, J=14.8,7.4 \mathrm{~Hz}, 2 \mathrm{H}) ;{ }^{13} \mathrm{C} \mathrm{NMR}\left(125 \mathrm{MHz}, \mathrm{DMSO}-d_{6}\right): \delta 169.66,163.80$, $161.76,157.26,138.43,138.35,138.21,133.65,131.70,129.07,128.73,125.34$, $125.07,124.60,123.99,115.82,114.56,114.04,113.13,46.54,30.38,29.86,28.82$, 27.87, 26.02, 21.69; HRMS calcd for $\mathrm{C}_{26} \mathrm{H}_{29} \mathrm{~N}_{5}{ }^{81} \mathrm{BrS}[\mathrm{M}+\mathrm{H}]^{+}$524.1301, found: 524.1310 。

\subsubsection{General procedure for synthesis of $\mathbf{6 e - 1}$.}

To a solution of $4 \mathbf{e}$ in DMF (5 mL) was added 1-bromohexane (5.0 equiv.), and the mixture was stirred at $50^{\circ} \mathrm{C}$ for $5 \mathrm{~h}$. Then, the reaction mixture was removed under vacuum and the residue was poured into ice water and extracted with ethyl acetate (3 $\times 50 \mathrm{~mL}$ ). The combined organic layers were washed with brine, dried over magnesium sulfate anhydrous. After filtration, the solvent was removed under vacuum 
and the residue was purified by silica gel column chromatography (petroleum ether/ethyl acetate 5:1) to give get the final target compound $\mathbf{6 e - 1}$.

\section{2-(6-(6-bromo-3-(2-(3-fluorophenyl)pyrimidin-4-yl)-1H-indol-1-yl)hexyl)isot}

hiouronium bromide (6e-1). Yield: 63\%; pale yellow solid; m.p. $85-87^{\circ} \mathrm{C}$; ${ }^{1} \mathrm{H}$ NMR (400 MHz, DMSO- $\left.d_{6}\right): \delta 8.78(\mathrm{~d}, J=5.4 \mathrm{~Hz}, 1 \mathrm{H}), 8.60(\mathrm{~s}, 1 \mathrm{H}), 8.54(\mathrm{~d}, J=8.6 \mathrm{~Hz}$, $1 \mathrm{H}), 8.36(\mathrm{~d}, J=7.9 \mathrm{~Hz}, 1 \mathrm{H}), 8.19$ (ddd, $J=10.6,2.5,1.5 \mathrm{~Hz}, 1 \mathrm{H}), 7.94$ (d, $J=1.6$ $\mathrm{Hz}, 1 \mathrm{H}), 7.82$ (d, $J=5.5 \mathrm{~Hz}, 1 \mathrm{H}), 7.68-7.60$ (m, 1H), 7.42 (ddd, $J=10.6,8.3,1.9 \mathrm{~Hz}$, 2H), $4.29(\mathrm{t}, J=7.1 \mathrm{~Hz}, 2 \mathrm{H}), 1.26(\mathrm{dd}, J=16.6,10.1 \mathrm{~Hz}, 8 \mathrm{H}), 0.84(\mathrm{~d}, J=7.0 \mathrm{~Hz}$, $3 \mathrm{H}) ;{ }^{13} \mathrm{C}$ NMR (100 MHz, DMSO- $\left.d_{6}\right): \delta 161.96,157.41,141.01,138.52,133.99$, $131.30,124.99,124.70,124.19,123.83,118.04,117.82,115.87,115.11,114.50$, 114.16, 112.91, 46.65, 31.23, 30.03, 26.24, 22.47, 14.33; HRMS: $m / z[\mathrm{M}+\mathrm{H}]^{+}$calcd for $\mathrm{C}_{24} \mathrm{H}_{24} \mathrm{~N}_{3} \mathrm{BrF}$, 452.1132; found, 452.1145 .

\subsubsection{General procedure for synthesis of $\mathbf{6 e - 2} \mathbf{6}$.}

To a solution of $4 \mathbf{e}$ in DMF $(5 \mathrm{~mL})$ was added 1,2-dibromoethane, 1,3-dibromopropane, 1,4-dibromobutane, 1,5-dibromopentane or 1,7-dibromoheptane (5.0 equiv.) respectively, and the mixture was stirred at $50^{\circ} \mathrm{C}$ for $5 \mathrm{~h}$. Then, the reaction mixture was removed under vacuum and the residue was poured into ice water and extracted with ethyl acetate $(3 \times 50 \mathrm{~mL})$. The combined organic layers were washed with brine, dried over magnesium sulfate anhydrous and concentrated to give intermediates 37 41, and used in the next step without further purification. To a stirring solution of compounds 37 41 in ethanol was added thiocarbamide (2.0 equiv.), and the mixture was stirred at $65^{\circ} \mathrm{C}$ for $3 \mathrm{~h}$. Then, the solvent was removed under vacuum and the residue was purified by silica gel column chromatography (dichloromethane/methanol 10:1) to give get the final target compounds 6e-2 6.

\section{2-(2-(6-bromo-3-(2-(3-fluorophenyl)pyrimidin-4-yl)-1H-indol-1-yl)ethyl)isoth}

iouronium bromide (6e-2). Yield: 60\%; pale yellow solid; m.p. 194-194 ${ }^{\circ} \mathrm{C}$; ${ }^{1} \mathrm{H}$ NMR (400 MHz, DMSO-d $\left.)_{6}\right): \delta 9.15(\mathrm{~s}, 2 \mathrm{H}), 9.01$ (d, $\left.J=25.1 \mathrm{~Hz}, 2 \mathrm{H}\right), 8.83$ (d, $J=$ $5.4 \mathrm{~Hz}, 1 \mathrm{H}), 8.62(\mathrm{~s}, 1 \mathrm{H}), 8.54(\mathrm{~d}, J=8.6 \mathrm{~Hz}, 1 \mathrm{H}), 8.36(\mathrm{~d}, J=7.9 \mathrm{~Hz}, 1 \mathrm{H})$, $8.22-8.17(\mathrm{~m}, 1 \mathrm{H}), 8.02(\mathrm{~d}, J=1.6 \mathrm{~Hz}, 1 \mathrm{H}), 7.81(\mathrm{~d}, J=5.4 \mathrm{~Hz}, 1 \mathrm{H}), 7.65(\mathrm{td}, J=8.0$, 
$6.1 \mathrm{~Hz}, 1 \mathrm{H}), 7.49(\mathrm{dd}, J=8.6,1.7 \mathrm{~Hz}, 1 \mathrm{H}), 7.43(\mathrm{td}, J=8.3,2.2 \mathrm{~Hz}, 1 \mathrm{H}), 4.64(\mathrm{t}, J=$ $6.4 \mathrm{~Hz}, 2 \mathrm{H}), 3.79-3.67$ (m, 2H); ${ }^{13} \mathrm{C}$ NMR (100 MHz, DMSO-d $)$ : $\delta 169.30,162.59$, $161.71,157.67,140.89,138.43,134.21,131.42,131.33,125.04,124.22,123.77$, 118.15, 117.94, 116.20, 115.24, 114.62, 114.37, 113.46, 45.41, 30.84; HRMS: $m / z$ [M $+\mathrm{H}]^{+}$calcd for $\mathrm{C}_{21} \mathrm{H}_{18} \mathrm{~N}_{5}{ }^{81} \mathrm{BrFS}, 472.0424$; found, 472.0427 .

\section{2-(3-(6-bromo-3-(2-(3-fluorophenyl)pyrimidin-4-yl)-1H-indol-1-yl)propyl)iso}

thiouronium bromide (6e-3). Yield: 45\%; pale yellow solid; m.p. $175-177{ }^{\circ} \mathrm{C}$; ${ }^{1} \mathrm{H}$ NMR (400 MHz, DMSO-d $\left.d_{6}\right): \delta 9.12(\mathrm{~s}, 2 \mathrm{H}), 8.98$ (s, 2H), $8.80(\mathrm{~d}, J=5.4 \mathrm{~Hz}, 1 \mathrm{H})$, $8.61(\mathrm{~s}, 1 \mathrm{H}), 8.56(\mathrm{~d}, J=8.6 \mathrm{~Hz}, 1 \mathrm{H}), 8.36(\mathrm{~d}, J=7.9 \mathrm{~Hz}, 1 \mathrm{H}), 8.22-8.16(\mathrm{~m}, 1 \mathrm{H})$, $7.97(\mathrm{~d}, J=1.6 \mathrm{~Hz}, 1 \mathrm{H}), 7.83(\mathrm{~d}, J=5.5 \mathrm{~Hz}, 1 \mathrm{H}), 7.65$ (td, $J=8.0,6.1 \mathrm{~Hz}, 1 \mathrm{H}), 7.47$ (dd, $J=8.6,1.7 \mathrm{~Hz}, 1 \mathrm{H}), 7.42(\mathrm{td}, J=8.3,2.1 \mathrm{~Hz}, 1 \mathrm{H}), 4.41(\mathrm{t}, J=6.9 \mathrm{~Hz}, 2 \mathrm{H}), 3.24$ - $3.16(\mathrm{~m}, 2 \mathrm{H}), 2.27-2.14(\mathrm{~m}, 2 \mathrm{H}) ;{ }^{13} \mathrm{C}$ NMR (100 MHz, DMSO- $\left.d_{6}\right): \delta$ 170.02, $164,18,162.52,161.86,157.51,140.98,140.83,138.49,133.91,131.39,124.99$, 124.22, 123.91, 117.90, 116.06, 115.24, 114.06, 113.32, 45.32, 29.73, 27.85; HRMS: $m / z[\mathrm{M}+\mathrm{H}]^{+}$calcd for $\mathrm{C}_{22} \mathrm{H}_{20} \mathrm{~N}_{5}{ }^{81} \mathrm{BrFS}, 486.0581$; found, 486.0583 .

2-(4-(6-bromo-3-(2-(3-fluorophenyl)pyrimidin-4-yl)-1 $H$-indol-1-yl)butyl)isoth iouronium (6e-4). Yield: 64\%; pale yellow solid; m.p. 171-173 ${ }^{\circ} \mathrm{C}$; ${ }^{1} \mathrm{H}$ NMR (400 MHz, DMSO-d $\left.d_{6}\right): \delta 9.05(\mathrm{~s}, 2 \mathrm{H}), 8.95(\mathrm{~s}, 2 \mathrm{H}), 8.79(\mathrm{~d}, J=5.5 \mathrm{~Hz}, 1 \mathrm{H}), 8.64(\mathrm{~s}, 1 \mathrm{H})$, $8.55(\mathrm{~d}, J=8.6 \mathrm{~Hz}, 1 \mathrm{H}), 8.36(\mathrm{~d}, J=7.9 \mathrm{~Hz}, 1 \mathrm{H}), 8.19$ (ddd, $J=10.5,2.5,1.4 \mathrm{~Hz}$, 1H), $7.99(\mathrm{~d}, J=1.6 \mathrm{~Hz}, 1 \mathrm{H}), 7.83(\mathrm{~d}, J=5.5 \mathrm{~Hz}, 1 \mathrm{H}), 7.65(\mathrm{td}, J=8.0,6.1 \mathrm{~Hz}, 1 \mathrm{H})$, 7.49-7.44 (m, 1H), $7.41(\mathrm{dd}, J=8.5,2.2 \mathrm{~Hz}, 1 \mathrm{H}), 4.40-4.30(\mathrm{~m}, 2 \mathrm{H}), 3.23(\mathrm{dd}, J=$ 15.2, 8.0 Hz, 2H), 1.99-1.89 (m, 2H), 1.64 (dt, $J=14.9,7.6 \mathrm{~Hz}, 2 \mathrm{H}) ;{ }^{13} \mathrm{C}$ NMR (100 MHz, DMSO): $\delta 170.17,162.52,161.92,161.80,157.42,140.93,138.48,134.04$, $131.38,124.93,124.23,123.88,118.06,117.89,116.00,115.14,114.59,114.19$, 113.05, 46.05, 30.06, 28.88, 26.37; HRMS: $m / z[\mathrm{M}+\mathrm{H}]^{+}$calcd for $\mathrm{C}_{23} \mathrm{H}_{22} \mathrm{~N}_{5}{ }^{81} \mathrm{BrFS}$, 500.0737; found, 500.0740.

\section{2-(5-(6-bromo-3-(2-(3-fluorophenyl)pyrimidin-4-yl)-1 $H$-indol-1-yl)pentyl)isot}

hiouronium (6e-5). Yield: 67\%; pale yellow solid; m.p. 155-157 ${ }^{\circ} \mathrm{C}$; ${ }^{1} \mathrm{H}$ NMR (400 MHz, DMSO-d $): \delta 9.02(\mathrm{~s}, 2 \mathrm{H}), 8.92(\mathrm{~s}, 2 \mathrm{H}), 8.78(\mathrm{t}, J=7.4 \mathrm{~Hz}, 1 \mathrm{H}), 8.64(\mathrm{~s}, 1 \mathrm{H})$, $8.55(\mathrm{~d}, J=8.6 \mathrm{~Hz}, 1 \mathrm{H}), 8.36(\mathrm{~d}, J=7.9 \mathrm{~Hz}, 1 \mathrm{H}), 8.19$ (ddd, $J=10.5,2.5,1.5 \mathrm{~Hz}$, 
1H), $7.96(\mathrm{~d}, J=1.6 \mathrm{~Hz}, 1 \mathrm{H}), 7.83(\mathrm{~d}, J=5.5 \mathrm{~Hz}, 1 \mathrm{H}), 7.65(\mathrm{td}, J=8.0,6.1 \mathrm{~Hz}, 1 \mathrm{H})$, 7.45 (dd, $J=8.6,1.7 \mathrm{~Hz}, 1 \mathrm{H}), 7.41$ (dd, $J=8.3,2.2 \mathrm{~Hz}, 1 \mathrm{H}), 4.37-4.28$ (m, 2H), 3.15-3.11 (m, 3H), $1.87(\mathrm{dd}, J=14.8,7.3 \mathrm{~Hz}, 2 \mathrm{H}), 1.65$ (dd, $J=14.5,7.4 \mathrm{~Hz}, 3 \mathrm{H})$, $1.43-1.37(\mathrm{~m}, 2 \mathrm{H}) ;{ }^{13} \mathrm{C}$ NMR (101 MHz, DMSO- $\left.d_{6}\right): \delta 170.30,162.53,161.96$, $157.41,140.96,138.52,134.06,131.37,125.01,124.77,124.22,123.85,117.87$, $115.93,115.13,114.41,114.40,114.13,112.96,46.48,30.32,29.47$, 28.52, 25.56; HRMS: $m / z[\mathrm{M}+\mathrm{H}]^{+}$calcd for $\mathrm{C}_{24} \mathrm{H}_{24} \mathrm{~N}_{5}{ }^{81} \mathrm{BrFS}, 514.0894$; found, 514.0898.

\section{2-(7-(6-bromo-3-(2-(3-fluorophenyl)pyrimidin-4-yl)-1H-indol-1-yl)heptyl)isot}

hiouronium (6e-6). Yield: 56\%; pale yellow solid; m.p. 121-123 ${ }^{\circ} \mathrm{C}$; ${ }^{1} \mathrm{H}$ NMR $(400$ MHz, DMSO-d $\left.d_{6}\right): \delta 9.00(\mathrm{~s}, 2 \mathrm{H}), 8.90(\mathrm{~s}, 2 \mathrm{H}), 8.79(\mathrm{~d}, J=5.4 \mathrm{~Hz}, 1 \mathrm{H}), 8.62(\mathrm{~s}, 1 \mathrm{H})$, $8.55(\mathrm{~d}, J=8.6 \mathrm{~Hz}, 1 \mathrm{H}), 8.36(\mathrm{~d}, J=7.9 \mathrm{~Hz}, 1 \mathrm{H}), 8.22-8.16(\mathrm{~m}, 1 \mathrm{H}), 7.95(\mathrm{~d}, J=1.6$ $\mathrm{Hz}, 1 \mathrm{H}), 7.83(\mathrm{~d}, J=5.5 \mathrm{~Hz}, 1 \mathrm{H}), 7.65(\mathrm{td}, J=8.0,6.1 \mathrm{~Hz}, 1 \mathrm{H}), 7.46(\mathrm{dd}, J=8.6,1.7$ $\mathrm{Hz}, 1 \mathrm{H}), 7.41(\mathrm{dd}, J=8.3,2.2 \mathrm{~Hz}, 1 \mathrm{H}), 4.31$ (t, $J=7.0 \mathrm{~Hz}, 2 \mathrm{H}), 3.11$ (t, $J=7.3 \mathrm{~Hz}$, 2H), 1.88-1.79 (m, 2H), $1.57(\mathrm{~d}, J=6.7 \mathrm{~Hz}, 2 \mathrm{H}), 1.32(\mathrm{~d}, J=11.1 \mathrm{~Hz}, 6 \mathrm{H}) ;{ }^{13} \mathrm{C} \mathrm{NMR}$ (100 MHz, DMSO- $\left.d_{6}\right): \delta 170.27,161.96,157.45,141.50,140.90,138.52,134.05$, $131.41,125.24,124.87,124.22,123.86,118.15,117.84,115.90,115.12,114.63$, 114.19, 112.91, 46.61, 30.47, 30.00, 28.70, 28.38, 28.16, 26.42; HRMS: $m / z[\mathrm{M}+\mathrm{H}]^{+}$ calcd for $\mathrm{C}_{26} \mathrm{H}_{28} \mathrm{~N}_{5}{ }^{81} \mathrm{BrFS}, 542.1207$; found, 542.1206.

\subsection{Biological evaluation}

Antibodies against p-Tyr1022/1023-JAK1, p-Tyr1007/1008-JAK2, p-Tyr980/981-JAK3, p-Tyr1054/1055-TYK2, pTyr705-STAT3, STAT3, c-Myc, CyclinD1 and Bcl-XL were obtained from Cell Signaling Technology (Beverly, USA), and antibodies against $\alpha$-tubulin and GAPDH were purchased from Santa Cruz Biotechnology (Santa Cruz, USA). Transfection Reagent, protease inhibitor and phosphatase inhibitor were purchased from Millipore (Billerica, USA). Polyvinylidene difluoride (PVDF) membranes and chemiluminescent horseradish peroxidase (HRP) substrate were purchased from Millipore (Billerica, USA). Gefitinib was acquired from Selleckchem (Huston, USA).

In vitro inhibitory activity. The resazurin indicator was used to evaluate cell 
viability. HeLa, MDA-MB-231, A549 and DU145 cells were seeded in 96-well plates in $50 \mu \mathrm{L}$ at plating densities ranging from 4000 to 8000 cells/well depending on the doubling time of individual cell lines. After incubation for $24 \mathrm{~h}$, different concentrations of compounds were added, and then the cells were further cultured for $72 \mathrm{~h}$, with $0.5 \%$ DMSO as the solvent control group and $10 \mu \mathrm{L}$ of resazurin solution $(1 \mathrm{mg} / \mathrm{mL})$ was directly added to each well as a redox indicator. Plates were incubated for $3 \mathrm{~h}$ to measure the absorbance of a SpectraMax@i3 (Molecular Devices, Madison, USA) of each well at a $595 \mathrm{~nm}$ emission wavelength (549 $\mathrm{nm}$ excitation wavelength). Each treatment was performed in triplicate to reduce the experimental error. Results were analyzed with GraphPad Prism 6 and data were shown as Mean $\pm \mathrm{SD}$.

Molecular Docking. All calculations were performed using Molecular Docking Program of MOE (version MOE 2020.09). The crystal structures of the proteins involved in this article were retrieved from the Protein Data Bank (PDB). Firstly, all compounds were treated through energy minimization. The parameters and charges were assigned with the MMFF94x force field. Secondly, after removing water molecules, each selected protein structures, was treated by adding hydrogen-atoms. Finally, the small molecules were docked into the pockets of the proteins defined by the originally bound ligands in the crystal structures, respectively. The poses are ranked by the scores from the GBVI/WSA binding free energy calculation, and the results were analyzed using Pymol (https://pymol.org/2/).

Flow cytometry analysis of apoptotic cells. An Annexin V-FITC/PI apoptosis kit (Invitrogen) was used to detect cell apoptosis. A549 and DU145 cells were cells at a density of $5 \times 10^{5}$ per well were cultured in regular growth medium in 6-well plates for $24 \mathrm{~h}$ and disposed induplicate with various concentrations of compound $6 \mathrm{e}$ for $24 \mathrm{~h}$. After $48 \mathrm{~h}$ later, the A549 and DU145 were trypsinized, centrifuged and washed with precooled PBS twice with an Annexin V-FITC/PI apoptosis kit (Invitrogen) following the manufacturer's instructions.

Western blot analysis. A549 and DU145 cells were plated in 6-well plates and cultured overnight respectively, and different concentrations of compound 6e were added for $2 \mathrm{~h}$. The corresponding cells were collected, washed with PBS and lysed 
with cell lysis buffer to extract the total proteins. The extracted protein was loaded, subjected to SDS-PAGE electrophoresis, and then the protein was transferred to a PDVF membrane and incubated in the corresponding Primary antibody overnight. The next day, the Primary antibody was recovered and labeled and the corresponding Secondary antibody was incubated. The immune complexes were detected using chemiluminescence HRP substrate (Millipore) and visualized by the Tanon 5200 Chemiluminescence Imaging System (Tanon Science and Technology Co., Ltd.).

In vivo studies. Six-week-old male nude mice (SPF degree, 17-20 g weight, nu/nu) were obtained from Beijing Vital River Laboratory Animal Technology Co. Ltd (Beijing, China). Nude mice were injected into the back with DU145 tumor cells (about $15 \times 10^{6}$ ). After 2 weeks, the mice were randomly divided into four groups: blank control group (NC, DMSO), positive control Gefitinib group (PC, $100 \mathrm{mg} / \mathrm{kg}$ ), compound 6e group $(5 \mathrm{mg} / \mathrm{kg})$ and compound 6e group $(10 \mathrm{mg} / \mathrm{kg})$, with 6 mice per group. The compound 6e groups and the PC group were intraperitoneally injected or intragastric administered every two days until the mice were sacrificed. The body weight of nude mice was recorded every three days, and the tumor weight was recorded on the day of death of nude mice All of the procedures were approved by the Committee of Experimental Animals of the Ocean University of China and conformed to the Guide for the Care and Use of Laboratory Animals published by the United States National Institutes of Health (NIH Publication No 85-23, revised 1996).

Immunohistochemistry (IHC) analyses. The mouse tumor tissues were collected, fixed in $4 \%$ PFA for $72 \mathrm{~h}$ at $4{ }^{\circ} \mathrm{C}$, embedded in paraffin, and cut into sections. The sections were deparaffinized in xylene, rehydrated in graded ethanol, boiled in antigen retrieval solution [31]. Then incubated with fresh $3 \% \mathrm{H}_{2} \mathrm{O}_{2}$ to inactivate endogenous peroxidase. After PBS washing, the slides were blocked with fatty free milk and incubated with primary antibody at $4{ }^{\circ} \mathrm{C}$ overnight, followed by incubation with the HRP-conjugated secondary antibody at room temperature (Boster, Wuhan, China) according to the manufacturer's instructions. Finally, DAB colour developing solution was added dropwise. A brown colour in the cell membrane indicated positive staining. Images were captured using an upright fluorescence microscope (Olympus BX53, 
Japan).

Author Contributions: Conceptualization, J.-Q.Z., R.Li., X-Y.D., C.-Y.Z. and T.J.; Methodology, J.-Q.Z., R.Li., X-Y.D., C.-Y.Z. and T.J.; Investigation, J.-Q.Z., R.Li., N.H., R.-J.Y., M.-K.Y. and J-Y.L.; Writing-original draft preparation, J.-Q.Z., R.Li. and T. J.; Writing-review and editing, J.-Q.Z., R.Li. and R.-L.Y.; Supervision, N.H., R.-J.Y. and M.-K.Y.; Funding acquisition, R.-L.Y., C.-Y.Z. and T.J. All authors have read and agreed to the published version of the manuscript.

\section{Acknowledgments}

The authors are grateful for financial support granted by the Natural Science Foundation of China (Grant No. 82073759), National Science and Technology Major Project for Significant New Drugs Development: 2018ZX09735004, Shandong Province Major Scientific and Technological Innovation Project 2020CXGC010503.

\section{Conflicts of interest}

The authors declare no other conflicts of interest.

\section{References}

[1] Aaronson, D.S.; Horvath, C.M. A road map for those who don't know JAK-STAT. Science. 2002, 296, 1653-1655.

[2] Murray, P.J. The JAK-STAT signaling pathway: input and output integration. J. Immunol. 2007, $178,2623-2629$

[3] Owen, K.L.; Brockwell, N.K.; Parker B.S. JAK-STAT signaling: a double-edged sword of immune regulation and cancer progression. Cancers. 2019, 11, 2002.

[4] Staerk, J.; Constantinescu, S.N. The JAK-STAT pathway and hematopoietic stem cells from the JAK2 V617F perspective. Jak-Stat. 2012, 1, 184-190.

[5] O"Shea, J.J.; Schwartz, D.M.; Villarino, A.V.; Gadina, M.; Mcinnes, I.B.; Laurence, A. The JAK-STAT pathway: impact on human disease and therapeutic intervention. Annu. Rev. Med. 2015, $66,311-328$.

[6] Li, H.X.; Zhao, W.; Shi, Y.; Li, Y.N.; Zhang, L.S.; Zhang, H.Q.; Wang, D. Retinoic acid amide 
inhibits JAK/STAT pathway in lung cancer which leads to apoptosis. Tumor. Biol. 2015, 36, $8671-8678$.

[7] Yu, H.; Kortylewski, M.; Pardoll, D. Crosstalk between cancer and immune cells: Role of STAT3 in the tumour microenvironment. Nat. Rev. Immunol. 2007, 7, 41-51.

[8] Yu, H.; Jove, R. The STATs of cancer-new molecular targets come of age. Nat. Rev. Cancer. 2004, 4, 97-105.

[9] Rawlings, J.S.; Rosler, K.M.; Harrison, D.A. The JAK/STAT signaling pathway. J. Cell. Sci. 2004, 117, 1281-1283.

[10] Franco, L.H.; Joffé, E.B.K.; Puricelli, L.; Tatian, M.; Seldes, A.M.; Palermo, J.A.J. Indole alkaloids from the tunicate aplidium meridianum. Nat. Prod. 1998, 61, 1130-1132.

[11] Gompel, M.; Leost, M.; Joffe. E.; Puricelli, L.; Franco, L.H.; Palermo, J.; Meijer, L. Meridianins, a new family of protein kinase inhibitors isolated from the ascidian Aplidium meridianum. Bioorg. Med. Chem. Lett. 2004, 14, 1703-1707.

[12] Radwan, M.A.; El-Sherbiny, M. Synthesis and antitumor activity of indolylpyrimidines: marine natural product meridianin D analogues. Bioorg. Med. Chem. 2007, 15, 1206-1211.

[13] Lebar, M.D.; Hahn, K.N.; Mutka, T.; Maiquan, P.; McClintock, J.B.; Amsler, C.D. CNS and antimalarial activity of synthetic meridianin and psammopemmin analogs. Bioorg. Med. Chem. 2011, 19, 5756-5762.

[14] Yadav, R.R.; Khan, S.I.; Singh, S.; Khan, I.A.; Vishwakarma, R.A.; Bharate, S.B. Synthesis, antimalarial and antitubercular activities of meridianin derivatives. Eur. J. Med. Chem. 2015, 98, $160-169$.

[15] Llorach-Pares, L.; Nonell-Canals, A.; Sanchez-Martinez, M.; Avila, C. Computer-aided drug design applied to marine drug discovery: meridianins as Alzheimer's disease therapeutic agents. Mar. drugs. 2017, 15, 366.

[16] Giraud, F.; Alves, G.; Debiton, E.; Nauton, L.; Théry, V.; Durieu, E.; Moreau, P. Synthesis, protein kinase inhibitory potencies and in vitro antiproliferative activities of meridianin derivatives. J. Med. Chem. 2011, 54, 4474-4489.

[17] Bettayeb, K.; Tirado, O.M.; Marionneau-Lambot, S.; Ferandin, Y.; Lozach, O.; Morris, J.C.; Meijer, L. Meriolins, a new class of cell death inducing kinase inhibitors with enhanced selectivity for cyclin-dependent kinases. Cancer. Res. 2007, 67, 8325-8334. 
[18] Echalier, A.; Bettayeb, K.; Ferandin, Y.; Lozach, O.; Clement, M.; Valette, A.; Meijer, L. Meriolins (3-(pyrimidin-4-yl)-7-azaindoles): synthesis, kinase inhibitory activity, cellular effects, and structure of a CDK2/cyclin A/meriolin complex. J. Med. Chem. 2008, 51, 737-751.

[19] Bharate, S.B.; Yadav, R.R.; Battula, S.; Vishwakarma, R.A. Meridianins: marine derived potent kinase inhibitors. Mini. Rev. Med. Chem. 2012, 12, 618-631.

[20] Regan, B.M.; Galysh, F.T.; Morris, R.N. The 2-thiopseudourea moiety, a newlocal anesthesiophore. J. Med. Chem. 1967, 10, 649-652.

[21] Davis, P.D.; Elliott, L.H.; Harris, W.; Hill, C.H.; Hurst, S.A.; Keech, E.; Wilkinson, S.E. Inhibitors of protein kinase C. 2. Substituted bisindolylmaleimides with improved potency and selectivity. J. Med. Chem. 1992, 35, 994-1001.

[22] Danilenko, V.N.; Simonov, A.Y.; Lakatosh, S.A.; Kubbutat, M.G.; Totzke, F.; Schächtele, C.; Preobrazhenskaya, M.N. Search for inhibitors of bacterial and human protein kinases among derivatives of diazepines $[1,4]$ annelated with maleimide and indole cycles. J. Med. Chem. 2008, $51,7731-7736$.

[23] Wang, H.; Yan, C. A small-molecule p53 activator induces apoptosis through inhibiting MDMX expression in breast cancer cells. Neoplasia. 2011, 13, 611-619.

[24] Heger, M.; van Golen, R.; Broekgaarden, M.; Michel, M.C. The molecular basis for the pharmacokinetics and pharmacodynamics of curcumin and its metabolites in relation to cancer. Pharmacol. Rev. 2014. 66, 222-307.

[25] Alcolea, V.; Plano, D.; Karelia, D.N.; Palop, A.; Amin, S.; Sanmartín, C, Sharma, A.K. Novel seleno- and thio-urea derivatives with potent in vitro activities against several cancer cell lines. Eur. J. Med. Chem. 2016, 2, 134-144.

[26] Tong, S.; Zhang, M.; Wang, S.X.; Yin, R.J.; Yu, R.L.; Wan, S.B.; Zhang, L. Isothiouronium modification empowers pyrimidine-substituted curcumin analogs potent cytotoxicity and golgi localization. Eur. J. Med. Chem. 2016, 123, 849-857.

[27] Dong, J.; Huang, S.S.; Hao, Y.N.; Wang, Z.W.; Liu, Y.X.; Li, Y.Q.; Wang, Q.M. Marine-natural-products for biocides development: first discovery of meridianin alkaloids as antiviral and ant-phytopathogenic-fungus agents. Pest. Manag. Sci. 2020, 76, 3369-3376.

[28] Mehndiratta, S.; Wang, R.S.; Huang, H.L.; Su, C.J.; Hsu, C.M.; Wu, Y.W.; Liou, J.P. 4-Indolyl-N-hydroxyphenylacrylamides as potent HDAC class I and IIB inhibitors in vitro and in 
vivo. Eur. J. Med. Chem. 2017, 134, 13-23.

[29] Corbel, B., Michaud, F., Meijer, L., Simon, G., Couthon-Gourves, H., Haelters, J.P., Kervarec, N. Towards the syntheses of N-H and N-alkylated derivatives of meridianins. J. Heterocycl. Chem. 2007, 44, 793-801.

[30] Lee, S.Y., Shin, W.R., Sekhon, S.S., Lee, J.P., Kim, Y.C., Ahn, J. Y., Kim, Y.H. Molecular docking analysis and biochemical evaluation of levansucrase from sphingobium chungbukense DJ77. ACS. Comb. Sci. 2018, 20, 414-422.

[31] Shao, S.; Yu, R.; Yu, Y.; Li, Y. Dual-inhibitors of STAT5 and STAT3: studies from molecular docking and molecular dynamics simulations. J. Mol. Model. 2014, 20, 1-17. 